\title{
Uma investigação e aplicação das novas medidas de alfabetização no Brasil
}

\author{
Felipe Garcia Ribeiro \\ PPGOM-UFPel \\ André Portela Fernandes de Souza \\ EESP/FGV
}

\section{Palavras-chave \\ medidas de alfabetização, analfabetos não isolados, analfabetos isolados, externalidades.}

Classificação JEL D63, IOO, O15.

\section{Key words:}

measures of literacy, proximate literate, isolated illiterate, externalities

JEL Classification $D 63, I O O$, O15.

\section{Resumo}

Este trabalho objetiva investigar o analfabetismo no Brasil com base no uso de medidas que utilizam os conceitos de externalidades da alfabetização e analfabetismo isolado. Entende-se por "analfabetos isolados" aqueles indivíduos analfabetos que não convivem com pessoas alfabetizadas. Para tanto, avalia-se o perfil de alfabetização da população brasileira com esses conceitos e aplicam-se as principais medidas de alfabetização desenvolvidas recentemente. Da investigação do perfil de alfabetização no país, constata-se ser a região Nordeste a que apresenta os piores resultados entre as demais, uma vez que é a que tem a maior parcela de analfabetos isolados do total. Além disso, a proporção de pessoas que residem em arranjos domiciliares com chefes solteiros, sem filhos e sem outros parentes é fortemente associada às variações nos rankings das diferentes medidas de alfabetização dos municípios do Nordeste.

\section{Abstract}

This paper aims at investigating illiteracy in Brazil in light of measures that deal with the concepts of externalities of literacy and the notion of isolated illiteracy. "Isolated illiterates" are considered those individuals who do not have contact with literate individuals. In order to do such investigation, the profile of literacy rates of the Brazilian population is evaluate based on such concepts, and then the main measures of literacy developed recently are applied. Such profile investigation shows that the Northeast region is the one that presents the worst results in the country, having the largest share of isolated illiterate individuals. In addition to that, the proportion of individuals in households with unmarried heads, without children and without relatives, is strongly associated with the variations in the rankings of the different kinds of illiteracy measures of the Northeastern municipalities. 


\section{1_Introdução}

Tradicionalmente se utiliza a taxa de alfabetização determinada pela razão entre $o$ total de pessoas alfabetizadas e o total da população como principal parâmetro informativo acerca da situaçáo da alfabetização de uma regiáo ou de um grupo de indivíduos. De acordo com Basu e Foster (1998), essa medida não capta os diferentes cenários de distribuição da alfabetização entre as famílias, sendo, portanto, limitada para informar com precisão o papel da alfabetização na definição do nível de bem-estar da sociedade. Por exemplo, a única informação obtida sobre a alfabetização de duas regióes com população de tamanhos idênticos e com metade dos indivíduos alfabetizados é que ela é exatamente a mesma para ambas as regiōes, 50,0\%. Contudo, pode ser que, em um caso, metade das famílias seja composta de pessoas alfabetizadas, e a outra metade, de pessoas analfabetas. No outro caso, pode ser que, em todas as famílias, metade de seus membros seja alfabetizada, e a outra metade, analfabeta. Essas são, portanto, duas situações inteiramente distintas que a medida tradicional de alfabetização não consegue revelar.

Basu e Foster (1998) argumentam que o fato de haver alguém que esteja apto a processar e a realizar atividades que requerem o uso da leitura e da escrita gera externalidades positivas para os demais membros analfabetos da família. ${ }^{1} \mathrm{Na}$ concepção deles, a alfabetização de pelo menos uma pessoa da família é um bem público para os demais membros analfabetos. ${ }^{2}$ Por exemplo, uma campanha de governo em prol da saúde pública em que há distribuição de panfletos explicativos sobre métodos de higiene e prevenção de possíveis doenças pode alcançar analfabetos que convivem com pessoas alfabetizadas, se estas compartilharem as informações contidas nos panfletos ou se adotarem as recomendaçóes da campanha em favor da família. Por outro lado, analfabetos isolados do convívio de pessoas alfabetizadas não teriam acesso às informações fornecidas pelo governo.

Em termos de bem-estar, portanto, a segunda situação do primeiro parágrafo pode ser superior à primeira, já que a existência de tais externalidades dentro da família pode melhorar as condições de vida dos membros analfabetos. Em decorrência disso, Basu e Foster (1998) sugerem a divisão dos analfabetos em duas categorias: Analfabetos Não Isolados e Analfabetos Isolados (de agora em diante ANI e AI, respectivamente). ${ }^{3} \mathrm{O}$ primeiro termo se refere aos analfabetos que convivem com pessoas alfabetizadas, ao passo que o segundo é referente aos analfabetos que não convivem com pessoas alfabetizadas.
Os benefícios da a dentro das famílias foram documentados inicialmente por Green et al. (1985).

${ }^{2}$ Basu e Foster (1998) restringem o escopo das externalidades da alfabetização à unidade domiciliar; entretanto, ressalvam que tais externalidades podem ser capturadas em redes mais amplas de contato dos indivíduos.

${ }^{3}$ Essas são traduções livres para os termos Proximate Literate e Isolated Iliterate. 
A distinção dos analfabetos, posta acima, é importante para efeitos de políticas públicas. Pode-se pensar que, diante de um dado orçamento para gastos do governo em educação, seja mais interessante em termos de melhoria de bem-estar que uma política de alfabetizaçáo destine-se a regióes em que a maior parte dos analfabetos esteja isolada do convívio de pessoas alfabetizadas. Tal política possibilitaria a criação de novas externalidades positivas da alfabetização através da educação de pessoas AI, uma vez que essas poderiam auxiliar outros indivíduos analfabetos nas atividades que necessitam do uso de leitura ou de escrita.

O presente trabalho visa introduzir essa discussão para o Brasil mediante a investigação do perfil de alfabetização da população brasileira com base nos conceitos de AI e ANI e da apresentação e aplicação das principais medidas desenvolvidas valendo-se de Basu e Foster (1998). Tal proposta é relevante pelo fato de que, como contém informações da distribuição da alfabetização entre as famílias, essas medidas podem auxiliar na elaboração de políticas públicas, tanto para diagnóstico como para uso de metas a ser alcançadas por tais políticas. Investiga-se também se, entre os diferentes arranjos domiciliares no país, há heterogeneidade no perfil de alfabetização quanto às definiçóes introduzidas neste artigo.
Embora a taxa de analfabetismo da população adulta venha caindo no Brasil, nas últimas décadas (de aproximadamente $20 \%$ em 1990 para $10,0 \%$ em 2009), ainda existe mais de 15 milhóes de pessoas analfabetas. Desse total, um quinto, ou 3 milhões de pessoas, encontra-se dentro da definição de analfabetismo isolado, estando, portanto, totalmente privado de usufruir de atividades que requerem o uso da escrita e da leitura. Dessa forma, o mapeamento do perfil de alfabetizaçáo via definições de AI e ANI e do uso das medidas alternativas é desejável para a quantificação correta da magnitude desse problema e sua localização.

Para a realização dos objetivos expostos acima, este trabalho se divide em duas partes principais. Primeiro se apresentam a literatura sobre externalidades da alfabetização e a problemática do analfabetismo no Brasil, por meio de uma discussão dos trabalhos realizados. Ainda na primeira parte, mas em outra seção, mostram-se em pormenores as medidas desenvolvidas por Basu e Foster (1998), Valenti (2002) e Subramanian (2004). A de Basu e Foster é apresentada neste artigo, porque é a primeira medida desenvolvida com a noção de externalidades da alfabetização. Já a medida de Valenti é exibida porque estende a medida de Basu e Foster no intuito de tratar a produção e a utiliza- 
ção dos benefícios das externalidades como função do número de alfabetizados e analfabetos de cada domicílio. Por fim, a medida de Subramanian é também apresentada em decorrência do esforço do autor em superar o possível problema informativo da medida de Basu e Foster (1998), decorrente do fato da medida desses autores ser quase sempre maior do que a medida tradicional (como será visto mais a frente). Segundo Subramanian (2004), tal problema pode levar a conclusão errônea de que existem mais pessoas alfabetizadas do que realmente há de fato. Essas três medidas serão discutidas em detalhes com o apontamento das vantagens e das desvantagens que cada uma oferece, e com a discussão das aplicações já realizadas em países subdesenvolvidos.

$\mathrm{Na}$ segunda parte do trabalho, detalha-se o perfil de alfabetização da população brasileira com o uso dos conceitos de ANI e AI e se aplicam as medidas apresentadas na segunda seção para os Estados e os diferentes arranjos domiciliares. O objetivo dessa seção é identificar possíveis grupos demográficos em que a presença de AI seja um traço mais marcante do que em outros. Por fim, será exibida uma síntese dos resultados encontrados e uma discussão sobre os rumos a ser seguidos por novos estudos sobre medidas e externalidades da alfabetização.
Cabe dizer que neste trabalho a definição de analfabetismo utilizada é a incapacidade de um indivíduo em ler e escrever no idioma que conhece. Embora existam outras definiçóes e métodos para a avaliação do status de alfabetização, essa questão não faz parte do escopo deste trabalho, que se restringe a apresentar e a aplicar as principais novas medidas e os conceitos adjacentes a elas (externalidades da alfabetização, ANI e AI). É importante dizer também que neste estudo o conceito de AI está restrito ao âmbito domiciliar, podendo ser expandido para outras redes de conexóes sociais mais amplas. ${ }^{4}$

\section{2_Literatura de externalidades da alfabetização $\mathrm{e} o$ analfabetismo no Brasil}

Do ponto de vista teórico, as externalidades positivas ocorrem quando um benefício externo é gerado pela produção de um bem, ou seja, ocorrem quando os benefícios sociais são superiores ao benefício privado. Nesse contexto, os benefícios privados da alfabetização podem ser percebidos, por exemplo, por meio dos salários obtidos em função do nível de escolaridade. Já os benefícios sociais da alfabetização podem ser notados tanto através de uma sociedade educada, capaz de obter melhores níveis de saúde e menores ín-
${ }^{4}$ Ver Maddox (2007). 
dices de criminalidade, quanto por meio de benefícios que indivíduos analfabetos em contato com pessoas alfabetizadas podem perceber em termos monetários ou em qualidade de vida.

Segundo Basu e Foster (1998), a alfabetizaçáo de pelo menos um membro da família gera externalidade positiva, proporcionando, desta forma, um bem público para os membros analfabetos. De acordo com a teoria econômica, um bem para ser considerado público exige que o seu consumo seja não excludente e não rival. Desse modo, no caso da alfabetização ser um bem público, a impossibilidade de exclusão em âmbito intradomiciliar sugere que os adultos analfabetos não poderiam ser privados de usufruir da alfabetização das demais pessoas que residem no mesmo domicílio. Já a não rivalidade no consumo sugere que, uma vez estando disponível o bem (no caso, a alfabetização de algum integrante do domicílio), o custo marginal de proporcioná-lo para um indivíduo adicional seria nulo.

Em decorrência do trabalho de Basu e Foster (1998), surgiram duas linhas de pesquisa sobre o tema. Uma se refere ao aprimoramento das medidas de alfabetização desenvolvidas por esses autores e novas aplicaçóes. Basicamente, procura-se explicitar os fatores que determinam a magnitude das externalidades ge- radas dentro das famílias e incorporar elementos que potencializam a capacidade informativa da desigualdade da alfabetização. Tais propostas são fundamentais para o balizamento de políticas públicas. Destacam-se nessa linha, além de Basu e Foster (1998), Valenti (2002) e Subramanian (2004), que serão discutidos em detalhes neste trabalho.

Outros estudos relevantes que se ocupam em aprimorar as medidas de alfabetização são os de Basu et al. (2000), Mishra (2001), Dutta (2004), Mukherjee e Gupta (2006), Maddox (2007), Basu e Lee (2008) e Lee (2008). Esses se debruçam em incorporar elementos importantes à formulação das medidas de alfabetização como aspectos demográficos e etnológicos.

Basu et al. (2000) fazem uma importante ressalva na proposição feita por Basu e Foster (1998): os benefícios da alfabetização, em geral, são não rivais, mas excludentes. Dessa maneira, a não rivalidade decorre da ausência de custos para que um alfabetizado possa ler um folheto ou dar uma informação a um analfabeto. A externalidade da alfabetização, poré $\mathrm{m}$, é excludente porque a pessoa alfabetizada, se quiser, pode ocultar alguma informação do analfabeto, uma vez que pode alterar a estrutura de poder dentro do domicílio, aumentando a capacidade de barganha dos analfabetos nas decisóes familiares. 
Já Mukherjee e Gupta (2006), em sua elaboração teórica, justificam a importância de caracterizar o perfil do alfabetizado e do analfabeto na formulação da medida. A incorporação dessas heterogeneidades individuais é considerada pelos autores como um avanço em relação às primeiras medidas alternativas de alfabetização, embora Valenti (2002) já trate dessa questão.

Ainda entre esses trabalhos com foco no desenvolvimento de medidas de alfabetização, a maior parte deles demonstra a aplicabilidade das medidas desenvolvidas utilizando informações de países como Índia e Bangladesh, fazendo uma comparação com os resultados obtidos da aplicação da medida de Basu e Foster (1998).

Já a outra linha de pesquisa é composta de trabalhos que focam a busca de evidências que corroboram a formulação teórica quanto à existência de externalidades da alfabetização. Basu et al. (2002), com dados do Household Expenditure Survey de Bangladesh 1995-1996, investigam se a produtividade no trabalho de chefes de família analfabetos é influenciada positivamente pela alfabetização dos demais membros. Basu e coautores constatam que a presença de indivíduos alfabetizados dentro da unidade familiar está associada a salários mais altos para os indivíduos analfabetos (tanto para homens quanto para mulheres). Por exemplo, ho- mens casados do setor urbano e do setor rural (não ligados a atividade agrária) recebem até $15,0 \%$ a mais quando têm na família ao menos um membro alfabetizado.

Gibson (2001), por meio da utilização de dados de Papua-Nova Guiné avalia o impacto da alfabetizaçáo de adultos em medidas de peso e saúde de crianças de até cinco anos de idade. A análise dos resultados revelou que os coeficientes associados às variáveis que representavam as externalidades da alfabetização se mostraram estatisticamente significantes e robustos, sendo, portanto, a alfabetização dos pais positiva para a saúde dos filhos. O autor também constata que a grandeza $\mathrm{da}$ externalidade responde às diferenças de gênero dos alfabetizados. Como era de se esperar, com base na maior parte dos trabalhos existente sobre o tema, os coeficientes estimados para a alfabetização das mães são maiores dos que os estimados para a alfabetização dos pais. Contudo, a hipótese nula de que os coeficientes que representam as variáveis de gênero diferentes sejam iguais $\left(\alpha^{m}=\alpha^{f}\right)$ não foi rejeitada, fato que, segundo o autor, deixa o tópico aberto para futuras pesquisas.

Já Almeyda-Duran (2005), baseando-se na hipótese de que as externalidades da alfabetização não se restringem apenas à unidade domiciliar, mas também a redes mais amplas de contato social, ava- 
liou o impacto da alfabetização de adultos, não pais, em indicadores de saúde das crianças da Índia com dados da $\mathrm{Na}$ tional Family Health Survey 1998-99. Da aplicação de regressóes de cross-sections e testes de robustez para a possível endogeneidade das equaçóes, as evidências encontradas sugerem que a alfabetização de mulheres impacta positivamente a saúde de crianças com pais analfabetos, ao passo que a alfabetização dos homens não se revela significante.

A investigação empírica da magnitude das externalidades tem por objetivo fornecer parâmetros para aplicação das medidas de alfabetização e substituir a utilização de valores ad hoc para a magnitude das externalidades, o que é feito até então e o que será realizado neste estudo. A utilização dos parâmetros estimados nos trabalhos supracitados ainda não é recomendável pelo fato de que o problema de causalidade reversa presente nas equaçóes estimadas não permite estabelecer a relação causal entre externalidades da alfabetização e benefícios sociais.

Já referente à problemática do analfabetismo no Brasil, são frequentes os estudos que visam identificar o perfil e a evolução da alfabetização da população, bem como o seu retorno privado. Souza (1999) aborda a evolução da alfabetização brasileira a partir da taxa de analfa- betismo, a qual é captada entre os anos de 1900 (65,0\%) e 1991 (20,0\%). De acordo com Souza, essa evolução depende tanto da dinâmica demográfica quanto da capacidade do sistema de ensino em alfabetizar indivíduos de todas as idades. Já a evolução da alfabetização por raça e sexo no Brasil, entre 1940 e 2000, foi analisada por Beltrão e Novellino (2002), os quais verificaram que pretos e pardos possuem entrada mais tardia na escola do que os demais indivíduos, bem como têm menor probabilidade de sucesso.

Nessa mesma linha, Barros et al. (2004) verificaram que a taxa de analfabetismo para a população negra é quase três vezes maior do que para a populaçáo branca, implicando que mais de 2/3 dos analfabetos sejam negros. Nesse mesmo estudo, foi constatado que a taxa de analfabetismo é bem maior entre os mais velhos (26,0\% para idosos de 55 a 64 anos) do que entre os mais jovens ( $4,0 \%$ para jovens de 15 a 24 anos).

Já De Baldini e Ponczek (2011) investigaram a importância da alfabetização sobre os rendimentos do trabalho dos analfabetos no Brasil. Os autores constataram que o acréscimo de produtividade em decorrência da alfabetização resulta em um aumento médio de 9,3\% no salário, e entre as mulheres a variação positiva da renda atinge $16,6 \%$. 
Como o presente estudo foca nas externalidades da alfabetização em âmbito intradomiciliar, torna-se relevante para a investigação do perfil da alfabetização não apenas as usuais características demográficas (cor, gênero, etc.), mas também os diferentes arranjos domiciliares. Nesse ponto, Medeiros e Osório (2000) analisaram as mudanças na composição dos arranjos domiciliares no Brasil, entre 1978 e 1998. Os arranjos domiciliares são compostos de núcleo (predominantemente formado pelo casal, ou, em alguns casos, apenas pelo chefe do domicílio) e de periferia (filhos e/ou demais familiares/agregados). No período analisado, as principais mudanças foram: "redução da proporçáo dos arranjos de núcleo composto (casal) e aumento, principalmente, dos arranjos de núcleo simples constituído por uma mulher (mulher com filhos)".

A estrutura domiciliar investigada por Medeiros e Osório (2000) é importante para o presente estudo, visto que é possível que determinados arranjos familiares possuam mais AI do que outros. Dessa forma, identificar essa possível heterogeneidade se torna crucial para a formulação de políticas públicas de erradicação do analfabetismo isolado e a ampliação das externalidades da alfabetização.

\section{3 _Medidas de alfabetização}

Cientes da inadequabilidade da medida tradicional de alfabetização para a avaliação do status da alfabetizaçáo em uma regiâo ou em um grupo demográfico, Basu e Foster (1998) desenvolveram uma medida que incorpora as externalidades da alfabetização. Tal medida foi denominada de alfabetização efetiva, $A E$, e tem como característica respeitar os seguintes axiomas:

Anonimato: para a computação da medida, não importam outras informações referentes aos indivíduos que não digam respeito ao status de alfabetização;

Monotonicidade: se ao menos um indivíduo alterar seu status de analfabeto para alfabetizado, e o status da população restante se mantiver inalterado, há incremento na magnitude da medida de alfabetização;

Decomposição: se uma região (ou um grupo de indivíduos) der origem a outras através de sua divisão, a medida de alfabetização da regiáo de origem pode ser obtida pela média ponderada das medidas das novas regióes pelas populaçóes resultantes da divisão; 
Normalização: se todos os indivíduos de uma região são alfabetizados, a medida tem que ser igual a um. Por outro lado, se todos os indivíduos são analfabetos, a medida tem que ser igual a zero. Em outras palavras, esse axioma requer que a medida de alfabetização expresse a proporção de alfabetizados do total da população e que ela independa do tamanho da população;

Externalidade: na divisão de um domicílio, há duas situaçôes distintas, com tudo mais constante:

1. A medida de alfabetização é a mesma antes e depois da divisão, já que não se alterou a distribuição dos alfabetizados entre os domicílios. Por exemplo, se houve a divisão de um domicílio que tinha dois indivíduos alfabetizados e após a divisão ficou um alfabetizado em cada domicílio, a medida não se altera;

2. A medida de alfabetização após a divisão é menor do que antes da divisão, uma vez que se alterou a distribuição dos alfabetizados. Por exemplo, um domicílio que tinha dois indivíduos alfabetizados e após a divisão um domicílio ficou com os dois alfabetizados e os demais domicílios resultantes da divisão sem nenhum, a medida se altera.

Percebe-se claramente que a medida tradicional de alfabetização satisfaz quase todas as características axiomáticas apresentadas acima à exceção da última. Já a medida de alfabetização efetiva satisfaz todas.

Para a definiçấo do perfil de alfabetização dos domicílios de uma regiáo de acordo com a ideia de externalidades da alfabetização, supóe-se que $x_{j}^{b}=1$ representa o fato de o indivíduo $j$ da família $h$ ser alfabetizado, e $x_{j}^{h}=0$ o fato de o indivíduo $j$ ser analfabeto. Dessa forma, tem-se que o perfil de alfabetização de um indivíduo $j$ pertencente à família $h$ será definido por

$x_{j}^{h}=\left\{\begin{array}{l}1 \text { se } x_{j}^{h}=1 \\ \alpha \text { se } x_{j}^{h}=0, \text { e } x_{k}^{h}=1 \text { para um } k \neq j \\ 0 \text { se } x_{j}^{h}=0, \forall j \in h\end{array}\right.$

onde $\alpha \in(0,1)$ representa a magnitude da externalidade gerada pela alfabetização do indivíduo $k$, que beneficia o indivíduo $j$ se este for analfabeto. Sendo assim, uma 
sociedade que tenha, por exemplo, dois domicílios com duas pessoas em cada, sendo que em um há uma pessoa alfabetizada e uma pessoa analfabeta, e no outro, duas pessoas analfabetas, terá o perfil de alfabetização do primeiro domicílio definido como $(1, \alpha)$, e do segundo, $(0,0)$.

Para a derivação da medida de alfabetização efetiva, defini-se $x_{j}^{*}$ como um indicador de acesso do indivíduo $j$ às funções que requerem alfabetização. Portanto, tem-se que $x_{j}^{*}$ será igual a 1 , se o indivíduo $j$ for alfabetizado, igual a $\alpha$ se ele for ANI, ou igual a 0 , se ele for AI. Isso posto, define-se a medida efetiva de alfabetização, AE, por

$$
A E=\frac{\sum_{j} x_{j}^{*}}{n}
$$

onde $n$ é o tamanho da população. Através de simples manipulação algébrica, pode se redefinir (3.2) para

$$
A E=T+\alpha P
$$

onde $T$ é a taxa de alfabetização usual, e $P$ é a proporção da população que é ANI.

É evidente que a magnitude de $\alpha$ dependerá de uma série de fatores que vão desde o número de alfabetizados e analfabetos presentes no domicilio à utilida- de marginal dos indivíduos alfabetizados em compartilhar com os analfabetos os benefícios da leitura e da escrita (Basu et al., 2000). No entanto, Basu e Foster (1998) realizaram mediçóes ilustrativas da $\mathrm{AE}$ em que atribuíram quatro valores para $\alpha: 0 ; 0,25 ; 0,50$ e 1 . Esses valores são estipulados de forma ad hoc e podem revelar diferentes estruturas de compartilhamento e recebimento das externalidades. Como já dito, a literatura empírica está debruçada sobre a tentativa de estimar o parâmetro $\alpha$, porém, ainda não há um consenso de que as evidências obtidas estejam protegidas dos clássicos problemas econométricos.

Da equação (3.3), constata-se claramente que a medida efetiva será superior à tradicional quando houver a presença de ANI na população e $\alpha>0$ Percebe-se que as medidas serão iguais apenas quando todos os indivíduos analfabetos estiverem isolados dos indivíduos alfabetizados. Quanto maior for a presença de ANI e/ou maior a magnitude das externalidades, maior será a medida de $A E$ em relação à tradicional. Fica claro que a medida tradicional se caracteriza como um caso particular da medida de $A E$.

Valenti (2002) aponta duas críticas para a medida desenvolvida por Basu e Foster (1998). A primeira delas se refere 
${ }^{5}$ Embora náo tratem as externalidades da alfabetização em função do número de alfabetizados e analfabetos em cada domicílio, Basu e Foster (1998) atentam para a possibilidade de externalidades diferenciadas em funçáo do gênero dos indivíduos alfabetizados. ao fato de que os autores consideram as externalidades da alfabetização bens públicos dentro da família. Entretanto, segundo Valenti, pode haver, por parte dos analfabetos, rivalidade no consumo das externalidades, o que as descaracterizariam como bens públicos.

Já a segunda crítica diz respeito à desconsideração dos autores com a possibilidade de que possa haver externalidades diferenciadas em função do número de alfabetizados e analfabetos dentro do domicílio. 5 Por exemplo, quanto maior o número de alfabetizados e menor o de analfabetos, maior é a disponibilidade de tempo que os alfabetizados terão para prover serviços que requerem uso da alfabetização para os analfabetos. Além disso, quanto maior for o número de alfabetizados, maior será a gama de serviços que poderão ser oferecidos aos analfabetos, uma vez que os indivíduos alfabetizados podem possuir habilidades diferentes e, portanto, realizar atividades e tarefas distintas.

Sob as duas críticas acima, a medida de $A E$ não leva em conta a possível presença de externalidades heterogêneas entre os diferentes tipos de domicílios. De acordo com Valenti (2002), as externalidades da alfabetização são função não apenas do perfil de alfabetização dos domicílios, mas também do número de pessoas presentes em cada unidade do- miciliar. Diferentes arranjos domiciliares podem apresentar diferentes externalidades da alfabetização.

Visando superar essas duas possíveis falhas na medida de alfabetização efetiva, Valenti (2002) desenvolve outra, denominada por medida de Alfabetização Sensível à Distribuição (daqui em diante $A S D$ ), capaz de capturar os retornos positivos e a rivalidade no consumo das externalidades dentro de cada unidade domiciliar. A principal alteração em relação à medida de Basu e Foster (1998) se refere ao fato de que a magnitude da externalidade é caracterizada como uma função da razão entre o número de alfabetizados e o número de analfabetos em cada família.

Em termos de construção teórica, a medida Alfabetização Sensível à Distribuição proposta por Valenti satisfaz igualmente como a medida de Basu e Foster (1998), os axiomas de anonimato, monotonicidade, decomposição e normalização. Contudo, Valenti (2002) substitui o axioma da externalidade por outro denominado de Igualdade e que apenas a sua medida satisfaz. Tal axioma garante que, quanto menor for a desigualdade da distribuição de alfabetizados e analfabetos entre os domicílios, maior é a medida de alfabetização.

Para tornar claro o que o axioma da Igualdade requer, pensa-se em uma so- 
ciedade com dois domicílios e com perfis de alfabetização inicialmente definidos por $(1,1,1, \alpha)$ e $(1, \alpha, \alpha, \alpha)$. Se um dos indivíduos alfabetizados do primeiro domicílio se mudar para o segundo, o perfil de alfabetização dessa sociedade fica $(1,1, \alpha, \alpha)$ e $(1,1, \alpha, \alpha)$. Como o número de alfabetizados e de ANI continua o mesmo, a aplicação da medida de $A E$ resulta em um mesmo valor para as duas situaçóes expostas acima. No entanto, segundo Valenti (2002), uma vez que há externalidades diferenciadas da alfabetização em função do número de alfabetizados e analfabetos em cada domicílio, a mudança de um alfabetizado do primeiro domicílio para o segundo altera a magnitude das externalidades nos dois domicílios. $\mathrm{O}$ que o axioma da Igualdade requer, nesse exemplo, é que uma medida de alfabetização seja maior no segundo caso do que no primeiro, já que agora os alfabetizados estão mais bem distribuídos na sociedade. É importante que se faça uma ressalva aqui: embora a medida de Valenti (2002) esteja sustentada no axioma da igualdade em vez de no axioma da externalidade, a noção de que a alfabetização gera externalidades para os indivíduos analfabetos segue mantida na medida de Valenti (2002) por construção.

Em síntese, das três medidas expostas até aqui, $T, A E$ e $A S D$, sabe-se que a pri- meira em nada aborda questóes distributivas da alfabetização na sociedade. Sabe-se também que, embora tenha o apelo de que, diante da existência de analfabetismo, é desejável a presença de alfabetizados convivendo com analfabetos, a medida de $A E$ tem por característica a não alteração da magnitude da externalidade da alfabetização quando aumenta (diminui) o número de pessoas alfabetizadas (analfabetas) em um domicílio que já tenha pelo menos algum membro alfabetizado. Por fim, a medida de $A S D$ traz em si a noção de que as externalidades da alfabetização não são bens públicos e dependem dos números de alfabetizados e analfabetos, e que a distribuição mais igualitária possível de alfabetizados e analfabetos é sempre desejável, uma vez que maximiza a magnitude das externalidades na sociedade.

Para a derivação da medida de $A S D$, primeiramente, tem-se que o perfil de alfabetização de um indivíduo que pertença à família $h$ é dado por

$$
x_{j}^{h}=\left\{\begin{array}{l}
1 \text { se } x_{j}^{h}=1 \\
\alpha=f\left(\frac{r_{h}}{s_{h}}\right) \text { se } x_{j}^{h}=0, \text { e } x_{k}^{h}=1 \text { para qualquer } k \neq j \\
0 \text { se } x_{j}^{h}=0, \forall j \in h
\end{array}\right.
$$

onde $r_{h}$ e $s_{b}$ são, respectivamente, o número de pessoas alfabetizadas e analfabetas da família $h$, e $\alpha$ é uma função da 
${ }^{6}$ Valenti (2002) demonstra que essa função, assim como as outras que ela propóe, satisfaz as propriedades de ser estritamente crescente e estritamente côncava. razão entre essas duas variáveis. Tal função que define $\alpha$ é por suposição estritamente crescente e estritamente côncava. Intuitivamente, a primeira suposição implica que, quanto mais pessoas alfabetizadas (ou menos analfabetas) houver dentro da família, maior é a magnitude da externalidade, enquanto a segunda significa que o ganho marginal na magnitude da externalidade, com o aumento no número de pessoas alfabetizadas (ou a redução do número de analfabetos), é decrescente. Sendo $H_{1}$ o conjunto de todas as famílias que tenham apenas pessoas alfabetizadas, e $\mathrm{H}_{2}$ o conjunto de todas as famílias em que haja ao menos uma pessoa analfabeta e uma alfabetizada, tem-se que a medida de Alfabetização Sensível à Distribuição é dada por:

$$
A S D=\frac{\sum_{b \in H_{1}} r_{b}+\sum_{b \in H_{2}}\left(r_{b}+\alpha\left(\frac{r_{b}}{s_{b}}\right) s_{h}\right)}{n}
$$

Percebe-se que a expressão (3.5) é muito semelhante à expressão (3.3), diferindo-se apenas na magnitude da externalidade $\alpha$, que em (3.5) é uma função de $r_{h}$ e $s_{b}$.

A decorrência direta de $\alpha$ estar em função de $r_{b}$ e $s_{b}$ é que, para a aplicação da medida Alfabetização Sensível à Distribuição, ao contrário da medida de Ba- su e Foster (1998), não é necessário que se estipulem valores a priori para o $\alpha$. Em contrapartida, é preciso que se defina uma regra que associe a magnitude das externalidades à razão pessoas alfabetizadas por pessoas analfabetas de cada família. Valenti (2002), em sua exposição, sugere algumas formas para tal função; entretanto, no exercício que realiza, utiliza a seguinte:

$$
\alpha=f\left(\frac{r_{h}}{s_{h}}\right)=\frac{\frac{r_{h}}{s_{b}}}{\frac{r_{b}}{s_{h}}+1}=\frac{r_{h}}{n_{h}}
$$

onde $n_{h}$ é o tamanho da família $h^{6}$

É preciso ser dito que, embora Valenti (2002) tenha avançado a discussão sobre medidas de alfabetização, explicitando o papel que a composição familiar exerce na geração das externalidades, a necessidade da especificaçáo de uma forma funcional ainda é uma limitação, assim como a estipulação ad hoc da magnitude das externalidades, como fazem Basu e Foster (1998). Nada garante que a magnitude das externalidades seja gerada de acordo com alguma forma funcional especifica em termos de parâmetros que caracterizem a composição familiar (número de alfabetizados e total de pessoas, por exemplo).

Seguindo na mesma direção de Valenti (2002), isto é, do aprimoramento da 
medida que Basu e Foster (1998) desenvolveram, Subramanian (2004) deriva outra que busca ligar externalidade, equidade e eficiência à medida de alfabetização efetiva. $\mathrm{O}$ autor destaca que, por ser sempre no mínimo igual à medida tradicional, a medida de Basu e Foster (1998) pode levar a conclusão equivocada de que há maior número de pessoas alfabetizadas do que realmente se verifica, o que pode levar a uma superestimação do bem-estar da sociedade. ${ }^{7}$ A medida que Subramanian (2004) desenvolve traz em si penalidades diretas para a distribuição desigual da alfabetização entre as famílias, sem desconsiderar as externalidades positivas que são geradas pela alfabetização.

Subramanian inicia a derivação de sua medida sugerindo um indicador de perda de eficiência para captar a existência de desigualdade na distribuição da alfabetização. A ideia de eficiência para esse caso merece atenção. Para um dado número de alfabetizados e analfabetos, a melhor distribuição em termos de bem-estar desses dois grupos seria aquela mais próxima da situação em que todos os analfabetos fossem ANI. Qualquer arranjo diferente desse acarretaria em menor bem-estar, que poderia ser evitado com melhor distribuição da alfabetização na sociedade. Isso posto, o indicador de perda de eficiência que Subramanian (2004) sugere penaliza a medida de alfabetização por existirem AI. Tal indicador é denotado por $Q$ e definido por:

$$
Q=\frac{I}{1-T}
$$

onde $I$ é a proporção de AI na população total. A medida $Q$ nada mais é do que a proporção de AI do total dos analfabetos (uma vez que 1-T é a proporção de analfabetos do total da população). Portanto, $Q$ tem como valor máximo 1 , quando $I$ é igual 1-T (situação em que todos os analfabetos estão isolados do convívio familiar com pessoas alfabetizadas), e tem como valor mínimo 0 , quando todos os analfabetos convivem com pelo menos uma pessoa alfabetizada. É claro que $T$ também impóe condiçóes sobre o valor de Q. Se, por exemplo, todos os indivíduos forem alfabetizados, o indicador de perda de eficiência não está definido.

De acordo com Subramanian (2004), seria desejável que determinada medida de alfabetização fosse uma função tanto da medida tradicional $T$ quanto do indicador de perda de eficiência. Tal medi$\mathrm{da}$, segundo o autor, ainda deve atender ao axioma de monotonicidade proporcional e aos intervalos e limites impostos em $T$ e $Q$

$\mathrm{O}$ axioma de monotonicidade proporcional garante que, para qualquer
${ }^{7}$ Por construçấo, a medida $A S D$ também está sujeita a esse mesmo problema. 
valor de $T$, uma alteração em $Q$ deve repercutir com uma mudança proporcional na medida de alfabetização que leva em conta essa perda de eficiência. Além disso, essa mudança proporcional deve depender do patamar em que $T$ se situa. Em outras palavras, esse axioma requer que uma medida de alfabetização esteja em função do indicador de perda de eficiência, e que uma variação de tal indicador repercuta de maneira distinta na medida a depender do patamar de alfabetização da sociedade. Dessa forma, em duas regiōes com o mesmo número de habitantes e com proporçôes diferentes de alfabetizados, uma variaçáo de mesma magnitude no indicador de perda de eficiência reflete em alterações distintas na medida de alfabetização. Esse axioma é fundamental para a construção de uma medida que penalize a existência de AI.

Com o axioma da monotonicidade proporcional e as condições de fronteira do indicador de perda de eficiência, o autor apresenta uma proposição que garante que a única medida capaz de atender a essas condiçóes é a medida de alfabetização ajustada para externalidades, $A A E$, definida por:

$$
A A E=T(1-I)
$$

Nota-se que o valor máximo que $A A E$ pode assumir é $T$ (quando não há
AI), e o valor mínimo, $T^{2}$ (quando todos os analfabetos são AI). Claramente, a presença de AI penaliza a medida de $A A E$, uma vez que $I$ e $A A E$ são negativamente relacionados. Dessa forma, essa medida será menor em regióes cujo grau de concentração da alfabetização é maior do que aquelas em que ela é mais bem distribuída na sociedade. Além disso, tem-se que $A A E \leq T$, o que reflete a superação daquele possível problema de interpretação do resultado das medidas de $A E$ e $A S D$ em que se pode pensar que há maior incidência de pessoas alfabetizadas, pelo fato de que essas medidas são sempre no mínimo iguais à medida tradicional. Outro elemento interessante da medida $A A E$ é que ela não requer nenhuma predição para o $\alpha$ nem para uma função que a defina, como necessitam as medidas $A E$ e $A S D$.

A Tabela 3.1, abaixo, relaciona as diferentes medidas de alfabetização e os axiomas que cada uma delas satisfaz.

\section{Tabela 3.1_Medidas de alfabetização e axiomas satisfeitos}

\begin{tabular}{l|c|c|c|c}
\multicolumn{1}{c|}{ Axioma/Medida } & T & AE & ASD & AAE \\
\hline Anonimato & $\mathrm{X}$ & $\mathrm{X}$ & $\mathrm{X}$ & $\mathrm{X}$ \\
\hline Monotonicidade & $\mathrm{X}$ & $\mathrm{X}$ & $\mathrm{X}$ & $\mathrm{X}$ \\
\hline Normalização & $\mathrm{X}$ & $\mathrm{X}$ & $\mathrm{X}$ & $\mathrm{X}$ \\
\hline Decomposição & $\mathrm{X}$ & $\mathrm{X}$ & $\mathrm{X}$ & $\mathrm{X}$ \\
\hline Externalidade & & $\mathrm{X}$ & & \\
\hline Igualdade & & & $\mathrm{X}$ & \\
\hline Monot. proporcional & $\ldots$ & $\ldots$ & $\ldots$ & $\mathrm{X}$.
\end{tabular}

Fonte: Basu e Foster (1998), Valenti (2002) e Subramanian (2004) 
As três medidas discutidas acima já foram aplicadas para outros países. Basu e Foster (1998) e Subramanian (2004) utilizaram a mesma base de dados, a saber: o censo da Índia para o ano de 1981, com o intuito de checar se o resultado obtido com a aplicação das medidas alternativas de alfabetização se diferenciaria dos resultados obtidos da aplicação da medida tradicional. Os primeiros autores constataram que os rankings de alfabetização dos Estados são sensíveis a diferentes medidas e à magnitude das externalidades da alfabetização. Já Subramanian, além de constatar o mesmo, verifica que o ajuste que penaliza a existência de analfabetos isolados é menos severo com os Estados em que a taxa de alfabetização tradicional é maior. Segundo ele, esse resultado não é surpreendente, porque a taxa de alfabetização tradicional e a proporção da população que é AI são em geral negativamente relacionadas.

Já com dados do October Household Survey de 1999, das províncias da África do Sul, Valenti (2002) mensura a alfabetização via uso da medida tradicional, da medida de alfabetização efetiva de Basu e Foster (1998) e da medida sensível à distribuição. Assim como Basu e Foster, ela constatou que o ranking de alfabetização por Estados se altera de acordo com as medidas que são aplicadas. Além disso, os Es- tados em que o grau de alfabetização da população é menor são os mais sensíveis à última medida. Em função desses resultados, Valenti (2002) recomenda para avaliação da alfabetização em países em desenvolvimento a aplicação de sua medida tanto para determinação de novos programas e políticas sociais quanto para a reavaliação dos programas e políticas já em curso.

\section{4_Perfil de alfabetização e aplicação das medidas para o Brasil}

Para a investigação da situação da alfabetização no Brasil com o uso dos conceitos de ANI e AI, a fonte de dados é a PNAD de 2009. Utiliza-se essa edição por se tratar da pesquisa mais recente e disponível das características socioeconômicas da população brasileira. Para tanto, primeiramente se faz um levantamento do número de alfabetizados e de analfabetos (sendo que esse é dividido entre ANI e AI). Mantém-se no universo de análise pessoas com 8 ou mais anos de idade. Tal postura é adotada para que toda a população de interesse já tenha idade suficiente para estar alfabetizada. ${ }^{8}$

A definição do status de alfabetização dos indivíduos foi baseada na pergunta direta "sabe ler ou escrever", presente na PNAD. Os indivíduos que assinalaram

\footnotetext{
${ }^{8}$ Acredita-se que, com essa população presente na amostra (pessoas de 8 a 9 anos de idade), aspectos relacionados ao trabalho infantil e a externalidades da alfabetização nas atividades características desse tipo de trabalho sejam captados no estudo. Além disso, a taxa de alfabetização para a populaçáo de 8 a 10 anos de idade em 2009 situa-se ao redor de $90 \%$, valor similar para o total da populaçáo com mais de 8 anos de idade.
} 
a resposta "sim" foram considerados alfabetizados, enquanto os que assinalaram a resposta "não" foram considerados analfabetos. Uma vez identificados esses dois grupos, a divisão dos analfabetos segundo as definiçóes de ANI e AI foi realizada por meio do perfil de alfabetizaçâo dos domicílios. Indivíduos analfabetos que residiam em domicílio com ao menos uma pessoa alfabetizada foram classificados como ANI, enquanto os que residiam em domicílios sem nenhum alfabetizado foram classificados como AI. A Tabela 4.1 apresenta em números o panorama geral da magnitude do problema do analfabetismo no país, de acordo com a noção de analfabetismo isolado.

\section{Tabela 4.1_AI, ANI, analfabetos e}

alfabetizados no Brasil em 2009

\begin{tabular}{l|r|r} 
Status & População & $\begin{array}{l}\text { Part. (\%) } \\
\text { no total }\end{array}$ \\
\hline AI & 3.224 .969 & $1,9 \%$ \\
\hline ANI & 11.953 .799 & $7,1 \%$ \\
\hline Analfabetos & 15.178 .768 & $9,0 \%$ \\
\hline Alfabetizados & 154.323 .739 & $91,0 \%$ \\
\hline Total & 169.502 .668 & $100,0 \%$ \\
\hline AI/Analfabetos (\%) & $\ldots 21,2 \%$ & $\ldots \ldots$ \\
\hline
\end{tabular}

Fonte: PNAD 2009.

Constata-se que a população de analfabetos no Brasil em 2009 é precisamente de 15.178 .768 pessoas, e as popula- ções de ANI e AI são, respectivamente, de 11.953.799 e 3.224.969 pessoas. A participação dos AIs no total dos analfabetos em 2009 é de $21,2 \%$. Tal fato revela que um pouco mais de um quinto do total dos analfabetos do país está excluído de informaçóes e serviços que requerem o uso de leitura e escrita, ao menos no nível domiciliar. Essa população de AI representa em 2009, aproximadamente, $2,0 \%$ do total da população.

A subseção 4.1 a seguir apresenta a distribuição da alfabetização pelas regiōes do país, localização dos domicílios, grupos de idade, raçalcor, sexo dos indivíduos e arranjos domiciliares. Após, a subseção 4.2 apresenta, para cada regiáo, setor de localização do domicílio, grupo de idade, raçalcor, sexo e arranjo domiciliar e o perfil de alfabetização dos indivíduos. Já a subseção 4.3 traz a aplicação das medidas de alfabetização para os Estados do Brasil e para os diferentes arranjos domiciliares.

\section{1_Investigação da distribuição da alfabetização}

Primeiramente, cabe comentar como foram definidas as variáveis grupos de idade e raça/cor. Para a construção da primeira, dividiu-se a população de interesse em quatro grupos: Crianças (8 a 15 anos), Jovens ( 16 a 24 anos), Adultos ( 25 a 59 anos) e Idosos (60 ou mais anos de idade). Já pa- 
ra a construção da variável raçalcor, agrupou-se as classificaçóes da PNAD em duas categorias, a saber, brancos (amarelos e brancos) e não brancos (pretos, pardos e indígenas). A definição da localização do domicílio segue a mesma sugerida pelo Instituto Brasileiro de Geografia e Estatística.

A partir disso, inicia-se a análise do estudo pelas regióes do país. A Tabela 4.2 mostra que mais da metade dos AIs (55,3\% do total) se encontra na regiāo Nordeste. Em termos absolutos, são 1.783.955 pessoas vivendo totalmente excluídas, pelo menos em nível domiciliar, dos benefícios de atividades que requerem o uso de escrita ou de leitura nessa região. Essa se trata de uma documentação importante da alfabetização no país, uma vez que indica a precariedade relativa da alfabetização no Nordeste em relação às demais regiôes, o que condiciona os esforços de políticas públicas de alfabetização para a região.

Já por localização do domicílio, constata-se que $35,7 \%$ do total dos analfabetos moram no setor rural, ao passo que apenas $13,7 \%$ dos alfabetizados estão nesse setor. Entre os AIs, o percentual de pessoas no setor rural é ainda maior, isto é, $41,1 \%$. Esse é outro resultado importante para a orientação de políticas públicas de alfabetização; nesse caso, em direção às regiōes rurais do país.
Em relaçáo à cor/raça, o resultado interessante novamente é para os analfabetos, uma vez que fica ao redor de $70 \%$ a participação dos não brancos no total dos analfabetos, dos ANIs e dos AIs. A distribuição dos alfabetizados entre não brancos e brancos é praticamente meio a meio (49,3\% e 50,7\%, respectivamente).

Por faixa etária, os dados da Tabela 4.2 revelam que metade dos alfabetizados, dos analfabetos e dos ANIs está na faixa etária adultos. Entretanto, tal resultado não é observado para os AIs, em que mais da metade deste grupo $(56,2 \%)$ pertence à faixa etária dos idosos.

Ressalta-se o fato de que as distribuiçóes de ANI e AI são muito similares entre as regiōes, cor e gênero. Apenas em localização do domicilio e faixa etária é que a distribuição de ANI e AI não coincide entre as categorias. Aliás, as principais diferenças encontradas na Tabela 4.2 referem-se aos idosos e ao meio rural. A maior participação de AI entre esses dois grupos sinaliza a ocorrência de um analfabetismo isolado crônico para idosos que moram sozinhos no meio rural.

Já a Tabela 4.3 abaixo traz a distribuição da população por status de alfabetização nos diferentes arranjos domiciliares. Há três núcleos domiciliares apresentados aqui: casal, homem solteiro chefe de domicílio e mulher solteira chefe de domicílio. ${ }^{9}$

\footnotetext{
${ }^{9}$ Para mais detalhes sobre composição e arranjos domiciliares, ver Medeiros e Osório (2000).
} 
Tabela 4.2_Distribuição dos alfabetizados, analfabetos, ANI e AI no Brasil em 2009

\begin{tabular}{|c|c|c|c|c|c|}
\hline & Variável & Alfabetizados & Analfabetos & ANI & Al \\
\hline \multirow{5}{*}{ 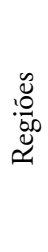 } & Norte & $7,7 \%$ & $8,5 \%$ & $8,8 \%$ & $7,3 \%$ \\
\hline & Nordeste & $25,2 \%$ & $52,6 \%$ & $51,8 \%$ & $55,3 \%$ \\
\hline & Sudeste & $44,4 \%$ & $25,0 \%$ & $25,4 \%$ & $23,6 \%$ \\
\hline & Sul & $15,3 \%$ & $8,1 \%$ & $8,1 \%$ & $8,1 \%$ \\
\hline & Centro-Oeste & $7,4 \%$ & $5,8 \%$ & $5,8 \%$ & $5,7 \%$ \\
\hline \multirow{2}{*}{ 䓪 } & Rural & $13,7 \%$ & $35,7 \%$ & $34,3 \%$ & $41,1 \%$ \\
\hline & Urbano & $86,3 \%$ & $64,3 \%$ & $65,7 \%$ & $58,9 \%$ \\
\hline \multirow{2}{*}{$\ddot{0}$} & Não brancos & $49,3 \%$ & $69,9 \%$ & $69,9 \%$ & $70,2 \%$ \\
\hline & Brancos & $50,7 \%$ & $30,1 \%$ & $30,1 \%$ & $29,8 \%$ \\
\hline \multirow{4}{*}{ 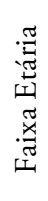 } & Crianças & $14,9 \%$ & $7,1 \%$ & $8,2 \%$ & $2,9 \%$ \\
\hline & Jovens & $21,2 \%$ & $4,3 \%$ & $4,5 \%$ & $3,2 \%$ \\
\hline & Adultos & $53,6 \%$ & $49,0 \%$ & $52,1 \%$ & $37,7 \%$ \\
\hline & Idosos & $10,2 \%$ & $39,7 \%$ & $35,2 \%$ & $56,2 \%$ \\
\hline \multirow{2}{*}{ 离 } & Homem & $48,2 \%$ & $49,5 \%$ & $49,7 \%$ & $48,8 \%$ \\
\hline & Mulher & $51,8 \%$ & $50,5 \%$ & $50,3 \%$ & $51,2 \%$ \\
\hline & Total & $100,0 \%$ & $100,0 \%$ & $100,0 \%$ & $100,0 \%$ \\
\hline
\end{tabular}

Fonte: PNAD 2009.

Percebe-se que os arranjos domiciliares que não contêm filhos são os que possuem o maior número de AI. Por exemplo, 23,3\% do total dos AIs do país está em domicílios em que o chefe é mulher solteira e sem filhos. Domicílios em que o chefe é mulher solteira, mas há filhos, contêm apenas 7,5\% dos AIs. Esse resultado pode ser explicado em parte pelo fato de que a taxa de alfabetização entre as crianças e os adolescentes é em torno de 95,0\%.

\section{2_Investigação da composição da população pelo status de alfabetização}

Novamente por regióes, o Nordeste é o que apresenta o pior resultado, isto é, $17,0 \%$ da sua população é analfabeta, da qual $13,2 \%$ é ANI, e 3,8\%, AI. Em termos de comparação, a segunda regiáo com o maior percentual de analfabetos é a Norte, com $9,8 \%$ da sua população nessa condição, sendo que apenas $1,8 \%$ é AI. As regióes Sul e Sudeste são as que apresentam a

Nova Economia_Belo Horizonte_23 (3)_73-100_setembro-dezembro de 2013 
Tabela 4.3_Distribuição dos alfabetizados, analfabetos, ANI e AI por tipos de arranjos domiciliares no Brasil em 2009

\begin{tabular}{|c|c|c|c|c|}
\hline Arranjos domiciliares & Alfabetizados & Analfabetos & ANI & Al \\
\hline Casal sem filhos & $11,7 \%$ & $17,1 \%$ & $13,0 \%$ & $32,4 \%$ \\
\hline Sem outros parentes & $9,4 \%$ & $12,5 \%$ & $7,9 \%$ & $29,2 \%$ \\
\hline Com outros parentes & $2,3 \%$ & $4,7 \%$ & $5,1 \%$ & $3,2 \%$ \\
\hline Casal com filhos & $62,8 \%$ & $50,9 \%$ & $60,7 \%$ & $14,8 \%$ \\
\hline Sem outros parentes & $49,7 \%$ & $34,5 \%$ & $40,3 \%$ & $12,9 \%$ \\
\hline Com outros parentes & $13,1 \%$ & $16,4 \%$ & $20,3 \%$ & $1,9 \%$ \\
\hline Homem solteiro sem filhos & $3,3 \%$ & $5,5 \%$ & $1,5 \%$ & $20,0 \%$ \\
\hline Sem outros parentes & $2,1 \%$ & $3,9 \%$ & $0,1 \%$ & $18,0 \%$ \\
\hline Com outros parentes & $1,2 \%$ & $1,5 \%$ & $1,4 \%$ & $2,0 \%$ \\
\hline Homem solteiro com filhos & $1,9 \%$ & $2,6 \%$ & $2,8 \%$ & $2,0 \%$ \\
\hline Sem outros parentes & $1,2 \%$ & $1,5 \%$ & $1,4 \%$ & $1,9 \%$ \\
\hline Com outros parentes & $0,7 \%$ & $1,1 \%$ & $1,4 \%$ & $0,2 \%$ \\
\hline Mulher solteira sem filhos & $4,2 \%$ & $7,9 \%$ & $3,7 \%$ & $23,3 \%$ \\
\hline Sem outros parentes & $2,1 \%$ & $4,6 \%$ & $0,2 \%$ & $20,8 \%$ \\
\hline Com outros parentes & $2,1 \%$ & $3,3 \%$ & $3,5 \%$ & $2,5 \%$ \\
\hline Mulher solteira com filhos & $15,7 \%$ & $15,8 \%$ & $18,1 \%$ & $7,5 \%$ \\
\hline Sem outros parentes & $9,1 \%$ & $7,9 \%$ & $8,4 \%$ & $6,3 \%$ \\
\hline Com outros parentes & $6,6 \%$ & $7,9 \%$ & $9,7 \%$ & $1,1 \%$ \\
\hline Total & $100,0 \%$ & $100,0 \%$ & $100,0 \%$ & $100,0 \%$ \\
\hline
\end{tabular}

menor participação de AI no total de sua população, com apenas $1,1 \%$ do total em ambas as regióes (Tabela 4.4).

Já por setor de localização do domicílio, a Tabela 4.4 abaixo informa que, no setor urbano, a proporção de alfabetizados $(93,2 \%)$ é maior do que no setor rural do país $(79,6 \%)$. Além disso, no rural aproximadamente $25 \%$ dos analfabetos são AI.
Já por raça/cor se destaca o fato de que, entre os não brancos, a taxa de analfabetismo é maior do que entre os brancos (12,2\% contra apenas 5,5\% dos brancos), e que aproximadamente $20 \%$ dos analfabetos não brancos são AI.

Quando se analisa o perfil de alfabetização dos grupos de idade, destaca-se que, para os grupos Crianças, Jovens e Adultos, 
o percentual de alfabetizados na população é superior a $90 \%$. Já para o grupo Idosos, tal percentual é bem inferior: $72,3 \%$. Ainda para os Idosos, destaca-se o fato de que $8,3 \%$ da população desse grupo etário é AI (resultado bem pior do que o verificado para as demais faixas de idade), o que vale dizer que aproximadamente $30 \%$ dos idosos é AI. Por fim, por sexo não se percebe novamente nenhuma diferença significativa entre homens e mulheres (Tabela 4.4).
Por arranjos domiciliares, a Tabela 4.5 apresenta o perfil de alfabetização. Percebe-se que os arranjos domiciliares homem ou mulher solteira sem filhos e sem outros parentes são os que apresentam as maiores parcelas de AI entre as suas populaçôes. Para mulheres solteiras sem filhos e sem outros parentes, o percentual de AI no total da população chega a $17,0 \%$, número bem acima dos $10 \%$ observados para o analfabetismo no Brasil. Esse resultado é surpreendente e aponta que a situação

Tabela 4.4_Perfil de alfabetização da população no Brasil em 2009

\begin{tabular}{|c|c|c|c|c|c|c|}
\hline & Variável & Alfabetizados & Analfabetos & ANI & Al & Total \\
\hline \multirow{5}{*}{ 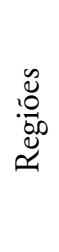 } & Norte & $90,2 \%$ & $9,8 \%$ & $8,1 \%$ & $1,8 \%$ & $100,0 \%$ \\
\hline & Nordeste & $83,0 \%$ & $17,0 \%$ & $13,2 \%$ & $3,8 \%$ & $100,0 \%$ \\
\hline & Sudeste & $94,7 \%$ & $5,3 \%$ & $4,2 \%$ & $1,1 \%$ & $100,0 \%$ \\
\hline & Sul & $95,0 \%$ & $5,0 \%$ & $3,9 \%$ & $1,1 \%$ & $100,0 \%$ \\
\hline & Centro-Oeste & $92,9 \%$ & $7,1 \%$ & $5,7 \%$ & $1,5 \%$ & $100,0 \%$ \\
\hline \multirow{2}{*}{$\begin{array}{l}\ddot{0} \\
\stackrel{0}{0}\end{array}$} & Rural & $79,6 \%$ & $20,4 \%$ & $15,4 \%$ & $5,0 \%$ & $100,0 \%$ \\
\hline & Urbano & $93,2 \%$ & $6,8 \%$ & $5,5 \%$ & $1,3 \%$ & $100,0 \%$ \\
\hline \multirow{2}{*}{$\dot{0}$} & Não brancos & $87,8 \%$ & $12,2 \%$ & $9,6 \%$ & $2,6 \%$ & $100,0 \%$ \\
\hline & Brancos & $94,5 \%$ & $5,5 \%$ & $4,4 \%$ & $1,2 \%$ & $100,0 \%$ \\
\hline \multirow{4}{*}{ 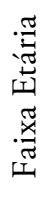 } & Crianças & $95,5 \%$ & $4,5 \%$ & $4,1 \%$ & $0,4 \%$ & $100,0 \%$ \\
\hline & Jovens & $98,1 \%$ & $1,9 \%$ & $1,6 \%$ & $0,3 \%$ & $100,0 \%$ \\
\hline & Adultos & $91,8 \%$ & $8,2 \%$ & $6,9 \%$ & $1,3 \%$ & $100,0 \%$ \\
\hline & Idosos & $72,3 \%$ & $27,7 \%$ & $19,4 \%$ & $8,3 \%$ & $100,0 \%$ \\
\hline \multirow{2}{*}{ 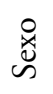 } & Homem & $90,8 \%$ & $9,2 \%$ & $7,2 \%$ & $1,9 \%$ & $100,0 \%$ \\
\hline & Mulher & $91,2 \%$ & $8,8 \%$ & $6,9 \%$ & $1,9 \%$ & $100,0 \%$ \\
\hline
\end{tabular}

Fonte: PNAD 2009. 
do AI está fortemente associada ao perfil do arranjo domiciliar. Como já constatado parcialmente na análise da distribuição das pessoas nos arranjos domiciliares, pessoas sozinhas estão mais sujeitas a padecerem com as consequências do analfabetismo isolado. Casal sem filhos e sem outros parentes aparece como a terceira estrutura com a maior parcela de AI, ou seja, 5,7\%.

Com o intuito de checar a apresentação da distribuição e do perfil da alfabetização brasileira pelas dimensóes utilizadas, procede-se a estimação de um logit multinomial para verificar a significância

\section{Tabela 4.5_Perfil de alfahetização da população no Brasil em 2009}

\begin{tabular}{|c|c|c|c|c|c|}
\hline Arranjos domiciliares & Alfabetizados & Analfabetos & ANI & AI & Total \\
\hline Casal sem filhos & & & & & \\
\hline Sem outros parentes & $88,5 \%$ & $11,5 \%$ & $5,8 \%$ & $5,7 \%$ & $100,0 \%$ \\
\hline Com outros parentes & $83,2 \%$ & $16,8 \%$ & $14,4 \%$ & $2,4 \%$ & $100,0 \%$ \\
\hline \multicolumn{6}{|l|}{ Casal com filhos } \\
\hline Sem outros parentes & $93,6 \%$ & $6,4 \%$ & $5,9 \%$ & $0,5 \%$ & $100,0 \%$ \\
\hline Com outros parentes & $89,0 \%$ & $11,0 \%$ & $10,7 \%$ & $0,3 \%$ & $100,0 \%$ \\
\hline \multicolumn{6}{|l|}{ Homem sem filhos } \\
\hline Sem outros parentes & $84,5 \%$ & $15,5 \%$ & $0,3 \%$ & $15,2 \%$ & $100,0 \%$ \\
\hline Com outros parentes & $89,1 \%$ & $10,9 \%$ & $7,9 \%$ & $3,0 \%$ & $100,0 \%$ \\
\hline \multicolumn{6}{|l|}{ Homem com filhos } \\
\hline Sem outros parentes & $88,8 \%$ & $11,2 \%$ & $8,3 \%$ & $2,9 \%$ & $100,0 \%$ \\
\hline Com outros parentes & $86,8 \%$ & $13,2 \%$ & $12,7 \%$ & $0,5 \%$ & $100,0 \%$ \\
\hline \multicolumn{6}{|l|}{ Mulher sem filhos } \\
\hline Sem outros parentes & $82,3 \%$ & $17,7 \%$ & $0,7 \%$ & $17,0 \%$ & $100,0 \%$ \\
\hline Com outros parentes & $86,5 \%$ & $13,5 \%$ & $11,3 \%$ & $2,2 \%$ & $100,0 \%$ \\
\hline \multicolumn{6}{|l|}{ Mulher com filhos } \\
\hline Sem outros parentes & $92,1 \%$ & $7,9 \%$ & $6,5 \%$ & $1,3 \%$ & $100,0 \%$ \\
\hline Com outros parentes & $89,5 \%$ & $10,5 \%$ & $10,2 \%$ & $0,3 \%$ & $100,0 \%$ \\
\hline Total & $91,0 \%$ & $9,0 \%$ & $7,1 \%$ & $2,0 \%$ & $100,0 \%$ \\
\hline
\end{tabular}

Fonte: ? 
e o sinal dos coeficientes estimados. Utilizam-se três categorias para a variável dependente, a saber: alfabetizados, ANI e AI. Nas duas primeiras colunas da Tabela 4.6, abaixo, a categoria de base para comparação da estimação do logit multinomial é alfabetizados. Já nas duas últimas colunas, a categoria base é analfabetos isolados.
Procede-se a estimação desses dois logits multinomiais para verificar com precisão os resultados obtidos da descrição da distribuição e do perfil da alfabetização.

As descrições da alfabetização no Brasil apresentadas nas Tabelas 4.4 e 4.5 são reforçadas pelos resultados das estimaçóes presentes na Tabela 4.6 em que se per-

Tabela 4.6_Estimações do logit multinomial para investigação da alfabetização no Brasil

\begin{tabular}{|c|c|c|c|c|}
\hline Variáveis & $\begin{array}{l}\text { ANI/alfabetizados } \\
\text { coef/dp }\end{array}$ & $\begin{array}{l}\text { Al/alfabetizados } \\
\text { coef/dp }\end{array}$ & $\begin{array}{l}\text { Alfabetizados/AI } \\
\text { coef/dp }\end{array}$ & $\begin{array}{l}\text { ANI/AI } \\
\text { coef/dp }\end{array}$ \\
\hline \multirow{2}{*}{ Norte } & $0,577^{* * *}$ & $0,494^{* * *}$ & $-0.494^{* * *}$ & 0.083 \\
\hline & $(0,028)$ & $(0,057)$ & $(0.057)$ & $(0.061)$ \\
\hline \multirow{2}{*}{ Nordeste } & $1,124^{* * *}$ & $1,271^{* * *}$ & $-1.271^{* * *}$ & $-0.147^{* * *}$ \\
\hline & $(0,020)$ & $(0,038)$ & $(0.038)$ & $(0.042)$ \\
\hline \multirow{2}{*}{ Sul } & $-0,037$ & $-0,013$ & 0.013 & -0.023 \\
\hline & $(0,031)$ & $(0,059)$ & $(0.059)$ & $(0.064)$ \\
\hline \multirow{2}{*}{ Centro-Oeste } & $0,281^{* * *}$ & $0,359^{* * *}$ & $-0.359^{* * *}$ & -0.079 \\
\hline & $(0,029)$ & $(0,055)$ & $(0.055)$ & $(0.061)$ \\
\hline \multirow{2}{*}{ Branco } & $-0,685^{* * *}$ & $-0,775^{* * *}$ & $0.775^{* * *}$ & $0.090^{* *}$ \\
\hline & $(0,018)$ & $(0,034)$ & $(0.034)$ & $(0.037)$ \\
\hline \multirow{2}{*}{ Setor urbano } & $-1,035^{* * *}$ & $-1,370^{* * *}$ & $1.370^{* * *}$ & $0.334^{* * *}$ \\
\hline & $(0,017)$ & $(0,030)$ & $(0.030)$ & $(0.031)$ \\
\hline \multirow{2}{*}{ Homem } & $0,078^{* * *}$ & $0,062^{* *}$ & $-0.062^{* *}$ & 0.016 \\
\hline & $(0,015)$ & $(0,028)$ & $(0.028)$ & $(0.030)$ \\
\hline \multirow{2}{*}{ Jovens } & $-0,777^{* * *}$ & $-0,118$ & 0.118 & $-0.659^{* * *}$ \\
\hline & $(0,043)$ & $(0,110)$ & $(0.110)$ & $(0.117)$ \\
\hline \multirow{2}{*}{ Adultos } & $0,898^{* * *}$ & $1,633^{* * *}$ & $-1.633^{* * *}$ & $-0.735^{* * *}$ \\
\hline & $(0,027)$ & $(0,079)$ & $(0.079)$ & $(0.082)$ \\
\hline \multirow{2}{*}{ Idosos } & $2,396^{* * *}$ & $3,956^{* * *}$ & $-3.956^{* * *}$ & $-1.561^{* * *}$ \\
\hline & $(0,029)$ & $(0,078)$ & $(0.078)$ & $(0.082)$ \\
\hline Observaçóes & 351.5 & & 351. & \\
\hline
\end{tabular}

Fonte: Elaboração própria. Nota: ${ }^{* * *} \mathrm{p}<0,01,{ }^{* *} \mathrm{p}<0,05,{ }^{*} \mathrm{p}<0,1$. 
cebe que estar na região Nordeste e ser da faixa etária dos idosos, condicionado às demais variáveis, aumenta a probabilidade relativa de se ser ANI e AI em relação a ser alfabetizado. Por outro lado, pertencer a um domicílio localizado no setor urbano e ser branco faz com que se tenha menor probabilidade relativa de ser ANI e AI em relação a ser alfabetizado.

Outro resultado interessante que pode ser observado nas duas primeiras colunas da tabela abaixo é que os coeficientes obtidos estimados para todas as características, exceto as de faixa etária, são muito similares. Esse resultado é a conseqüência do fato já observado anteriormente, isto é, que a proporção de ANI e AI nas características demográficas abaixo é muito similar, menos nos grupos etários. Tal constatação reforça a hipótese de que o AI está mais presente entre a população dos idosos. Os resultados obtidos na estimação do segundo logit também reforçam esse resultado: para quase todas as características, os coeficientes estimados são baixos, exceto idosos, em que a probabilidade de ser ANI em relação à $\mathrm{AI}$ é bem inferior (última coluna Tabela 4.6).

\section{3_Aplicação das medidas de alfabetização}

Assim como para a investigação do perfil de alfabetização da população brasileira, utiliza-se a PNAD de 2009 para a realização do exercício que consiste em aplicar as medidas desenvolvidas por Basu e Foster (1998), Valenti (2002), Subramanian (2004) e a medida tradicional para fins de comparaçáo. Mais uma vez, excluem-se da amostra as crianças com menos de 8 anos de idade.

Para aplicação da medida de Basu e Foster (1998), $A E$, estipula-se ad hoc valores para o parâmetro da expressão (3.3) assim como os próprios autores fazem em seu exercício e já justificado neste trabalho. Portanto, supor-se-ão externalidades de magnitudes $0,25,0,5$ e 0,75 . Já para a aplicação da medida sensível à distribuição de Valenti (2002), $A S D$, usa-se a função apresentada em 3.6, que é a mesma utilizada pela autora em seu trabalho.

A Tabela 4.7 apresenta os resultados da aplicação das medidas para os Estados do Brasil. As colunas que identificam as unidades da Federação para as medidas de Basu e Foster (1998), Valenti (2002) e Subramanian (2004) apresentam perdas de posição nos rankings em relação à medida tradicional de alfabetizaçáo, caso tenham ocorrido.

Destacam-se os Estados do AP e do RJ, como também o DF, com os melhores resultados em todas as medidas, sempre com taxas de alfabetização superiores a $95,5 \%$. Além disso, entre as dez primeiras posiçóes, se percebe alternância de posição entre RS, SC e SP da $4^{a}$ à $6^{a}$ posição, 
e alternância entre PR e AM, da $8^{a}$ à $9^{a}$ posição. Nas posições intermediárias do ranking, há mais algumas alteraçōes en- tre os Estados. O ES, por exemplo, na medida tradicional, aparece na $10^{a}$ posição, mas cai para $12^{\mathrm{a}}$ na medida de Subrama-

Tabela 4.7_Aplicação das medidas nos Estados do Brasil em 2009

\begin{tabular}{|c|c|c|c|c|c|c|c|c|c|c|c|c|}
\hline & UF & $\mathbf{T}$ & UF & AE025 & UF & AE05 & UF & AE075 & UF & ASD & UF & S \\
\hline $1^{\circ}$ & AP & $97,2 \%$ & AP & $97,8 \%$ & $\mathrm{AP}$ & $98,5 \%$ & $\mathrm{AP}$ & $99,1 \%$ & AP & $98,9 \%$ & $\mathrm{AP}$ & $97,0 \%$ \\
\hline $2^{\circ}$ & DF & $96,9 \%$ & DF & $97,6 \%$ & $\mathrm{DF}$ & $98,2 \%$ & $\mathrm{DF}$ & $98,9 \%$ & DF & $98,6 \%$ & DF & $96,5 \%$ \\
\hline $3^{\circ}$ & $\mathrm{RJ}$ & $96,3 \%$ & $\mathrm{RJ}$ & $97,0 \%$ & RJ & $97,7 \%$ & RJ & $98,5 \%$ & $\mathrm{RJ}$ & $98,1 \%$ & $\mathrm{RJ}$ & $95,5 \%$ \\
\hline $4^{\circ}$ & RS & $95,7 \%$ & RS & $96,6 \%$ & RS & $97,4 \%$ & $\mathrm{SP}(+2)$ & $98,3 \%$ & $\mathrm{SP}(+2)$ & $97,8 \%$ & RS & $94,8 \%$ \\
\hline $5^{\circ}$ & SC & $95,6 \%$ & SC & $96,5 \%$ & $\mathrm{SP}(+1)$ & $97,4 \%$ & SC & $98,3 \%$ & SC & $97,7 \%$ & SC & $94,8 \%$ \\
\hline $6^{\circ}$ & SP & $95,5 \%$ & SP & $96,5 \%$ & $S C(-1)$ & $97,4 \%$ & $\mathrm{RS}(-2)$ & $98,2 \%$ & $\mathrm{RS}(-2)$ & $97,7 \%$ & SP & $94,8 \%$ \\
\hline $7^{\circ}$ & RR & $94,5 \%$ & $\mathrm{RR}$ & $95,6 \%$ & $\mathrm{RR}$ & $96,7 \%$ & RR & $97,9 \%$ & $\mathrm{RR}$ & $97,4 \%$ & $\mathrm{RR}$ & $93,5 \%$ \\
\hline $8^{\circ}$ & PR & $94,0 \%$ & PR & $95,2 \%$ & $\operatorname{AM}(+1)$ & $96,4 \%$ & $\operatorname{AM}(+1)$ & $97,8 \%$ & $\operatorname{AM}(+1)$ & $97,1 \%$ & $\operatorname{AM}(+1)$ & $92,8 \%$ \\
\hline $9^{\circ}$ & $\mathrm{AM}$ & $93,6 \%$ & $\mathrm{AM}$ & $95,0 \%$ & $\operatorname{PR}(-1)$ & $96,4 \%$ & $\mathrm{PR}(-1)$ & $97,5 \%$ & $\mathrm{PR}(-1)$ & $96,8 \%$ & PR $(-1)$ & $92,8 \%$ \\
\hline $10^{\circ}$ & ES & $92,4 \%$ & MS $(+1)$ & $93,9 \%$ & MS $(+1)$ & $95,4 \%$ & $\mathrm{MS}(+1)$ & $97,0 \%$ & $\mathrm{MS}(+1)$ & $96,0 \%$ & $\mathrm{MS}(+1)$ & $91,0 \%$ \\
\hline $11^{\circ}$ & MS & $92,4 \%$ & $\mathrm{ES}(-1)$ & $93,8 \%$ & $\mathrm{MG}(+1)$ & $95,3 \%$ & $\mathrm{MG}(+1)$ & $96,8 \%$ & MG(+1) & $95,9 \%$ & MG $(+1)$ & $90,8 \%$ \\
\hline $12^{\circ}$ & MG & $92,3 \%$ & MG & $93,8 \%$ & $\mathrm{ES}(-2)$ & $95,3 \%$ & $\mathrm{GO}(+1)$ & $96,8 \%$ & $\mathrm{GO}(+1)$ & $95,9 \%$ & $\mathrm{ES}(-2)$ & $90,7 \%$ \\
\hline $13^{\circ}$ & $\mathrm{GO}$ & $92,3 \%$ & $\mathrm{GO}$ & $93,8 \%$ & $\mathrm{GO}$ & $95,3 \%$ & $\mathrm{ES}(-3)$ & $96,7 \%$ & ES(-3) & $95,8 \%$ & $\mathrm{GO}$ & $90,7 \%$ \\
\hline $14^{\circ}$ & RO & $91,2 \%$ & RO & $93,0 \%$ & RO & $94,8 \%$ & $\mathrm{RO}$ & $96,6 \%$ & RO & $95,4 \%$ & $\mathrm{RO}$ & $89,7 \%$ \\
\hline $15^{\circ}$ & MT & $90,9 \%$ & MT & $92,7 \%$ & MT & $94,5 \%$ & MT & $96,3 \%$ & MT & $95,1 \%$ & MT & $89,2 \%$ \\
\hline $16^{\circ}$ & PA & $88,2 \%$ & PA & $90,6 \%$ & PA & $93,0 \%$ & PA & $95,4 \%$ & PA & $93,6 \%$ & PA & $86,3 \%$ \\
\hline $17^{\circ}$ & $\mathrm{TO}$ & $88,2 \%$ & TO & $90,4 \%$ & $\mathrm{TO}$ & $92,6 \%$ & $\mathrm{AC}(+1)$ & $94,9 \%$ & TO & $93,2 \%$ & TO & $85,5 \%$ \\
\hline $18^{\circ}$ & $\mathrm{AC}$ & $86,1 \%$ & AC & $89,0 \%$ & AC & $91,9 \%$ & $\mathrm{TO}(-1)$ & $94,8 \%$ & AC & $92,7 \%$ & $\mathrm{AC}$ & $84,2 \%$ \\
\hline $19^{\circ}$ & SE & $85,0 \%$ & SE & $87,9 \%$ & SE & $90,8 \%$ & SE & $93,7 \%$ & SE & $91,5 \%$ & SE & $82,1 \%$ \\
\hline $20^{\circ}$ & BA & $84,8 \%$ & BA & $87,7 \%$ & BA & $90,6 \%$ & $\mathrm{RN}(+3)$ & $93,7 \%$ & BA & $91,4 \%$ & BA & $81,7 \%$ \\
\hline $21^{\circ}$ & PE & $83,8 \%$ & PE & $86,9 \%$ & $\mathrm{RN}(+2)$ & $90,1 \%$ & $\mathrm{BA}(-1)$ & $93,5 \%$ & $\mathrm{CE}(+1)$ & $90,9 \%$ & $\mathrm{RN}(+2)$ & $80,7 \%$ \\
\hline $22^{\circ}$ & $\mathrm{CE}$ & $83,3 \%$ & $\mathrm{CE}$ & $86,7 \%$ & CE & $90,0 \%$ & CE & $93,3 \%$ & $\mathrm{RN}(+1)$ & $90,9 \%$ & $\mathrm{CE}$ & $80,6 \%$ \\
\hline $23^{\circ}$ & RN & $83,0 \%$ & $\mathrm{RN}$ & $86,5 \%$ & $\mathrm{PE}(-2)$ & $90,0 \%$ & $\operatorname{PE}(-2)$ & $93,0 \%$ & $\operatorname{PE}(-2)$ & $90,8 \%$ & $\operatorname{PE}(-2)$ & $80,5 \%$ \\
\hline $24^{\circ}$ & MA & $82,6 \%$ & MA & $86,0 \%$ & MA & $89,4 \%$ & MA & $92,8 \%$ & MA & $90,1 \%$ & MA & $79,5 \%$ \\
\hline $25^{\circ}$ & PB & $80,5 \%$ & PB & $84,2 \%$ & PB & $88,0 \%$ & $\mathrm{~PB}$ & $91,8 \%$ & $\mathrm{~PB}$ & $88,8 \%$ & PB & $76,9 \%$ \\
\hline $26^{\circ}$ & PI & $78,7 \%$ & PI & $82,9 \%$ & PI & $87,1 \%$ & PI & $91,3 \%$ & PI & $87,8 \%$ & PI & $75,1 \%$ \\
\hline $27^{\circ}$ & AL & $78,1 \%$ & $\mathrm{AL}$ & $82,2 \%$ & $\mathrm{AL}$ & $86,3 \%$ & $\mathrm{AL}$ & $90,4 \%$ & $\mathrm{AL}$ & $87,1 \%$ & $\mathrm{AL}$ & $73,8 \%$ \\
\hline & Brasil & $91,0 \%$ & Brasil & $92,8 \%$ & Brasil & $94,6 \%$ & Brasil & $96,3 \%$ & Brasi & $95,1 \%$ & Brasil & $89,3 \%$ \\
\hline
\end{tabular}

Fonte: Elaboração própria. 
nian (2004), sendo ultrapassado por MS e MG, indicando maior presença de AI na sua população do que nos outros dois Estados. Ademais, ainda o ES é ultrapassado por GO nas medidas de Basu e Foster (1998) em função da intensidade das externalidades da alfabetização. Tal fato revela que, no Estado de GO, há maior parcela de ANI do que no ES.

Os Estados do MA, de PE, do PI e de AL são os quatro piores, respectivamente, nessa ordem em todas as medidas. $\mathrm{O}$ Estado do AL é o que apresenta a maior diferença entre a medida tradicional e a medida de Subramanian (2004), ou seja, 4,3\%, o que revela a precariedade da alfabetização nesse Estado em razão da expressiva existência de analfabetismo isolado Em síntese, os Estados da regiāo Nordeste do país são os que apresentam as piores colocações em todas as medidas. Esse resultado está de acordo com os obtidos da investigação da distribuição e do perfil do analfabetismo no Brasil.

Outra constatação interessante é que, a partir do momento em que se aumenta a magnitude das externalidades, amplia-se também a variação dos rankings. Na aplicação da medida $A E(0,25)$, ocorrem apenas duas variaçóes, ao passo que, na aplicação da medida $A E(0,75)$, ocorrem 13. Esse é um resultado importante pelo fato de que neste exercício se está tanto traba- lhando com valores ad hoc para magnitude das externalidades, supondo que a magnitude é a mesma para todos os Estados. Nada garante, porém, que isso seja verdade. É bastante razoável imaginar, por exemplo, que, em cada região, Estado e localização de domicílio, a magnitude das externalidades da alfabetização seja diferente, o que certamente introduziria mais sensibilidade aos rankings quando aplicado às medidas de $A E$. Dessa forma, na presença de um alto valor para a magnitude das externalidades ou grande heterogeneidade entre os Estados, com tudo mais constante, a aplicação das medidas pode gerar resultados bem diferentes, o que seria importante para a análise de custo e beneficio de políticas públicas de alfabetização.

Com o foco de explorar a já vista importância dos arranjos domiciliares na concentração de analfabetos isolados, aplicam-se as mesmas medidas utilizadas no exercício acima para os tipos de arranjos domiciliares utilizados até então. A Tabela 4.8, ao lado, apresenta os resultados.

Percebe-se que, para os tipos de arranjos domiciliares, ocorre para as posiçôes intermediárias na medida de alfabetização tradicional maior variação de posição quando se aplicam as diversas medidas. Por exemplo, o arranjo domiciliar casal sem filhos e sem outros parentes (arranjo 1) cai da terceira posição na medi- 
Tabela 4.8_Aplicação das medidas por arranjos domiciliares no Brasil em 2009

\begin{tabular}{|c|c|c|c|c|c|c|c|c|c|c|c|}
\hline Arranjos & $\mathbf{T}$ & Arranjos & AE0.25 & Arranjos & AE0.5 & Arranjos & AE0.75 & Arranjos & LPV & Arranjos & s \\
\hline 3 & $93,0 \%$ & 3 & $94,6 \%$ & 3 & $96,3 \%$ & 3 & $97,9 \%$ & 3 & $96,5 \%$ & 3 & $92,6 \%$ \\
\hline 11 & $92,0 \%$ & 11 & $93,7 \%$ & 11 & $95,4 \%$ & $12(+2)$ & $97,2 \%$ & 11 & $95,6 \%$ & 11 & $90,9 \%$ \\
\hline 1 & $91,5 \%$ & 1 & $92,6 \%$ & $12(+1)$ & $94,7 \%$ & $11(-1)$ & $97,1 \%$ & $12(+1)$ & $95,5 \%$ & $12(+1)$ & $89,3 \%$ \\
\hline 12 & $89,6 \%$ & 12 & $92,1 \%$ & $4(+2)$ & $94,4 \%$ & $4(+2)$ & $97,1 \%$ & $4(+2)$ & $95,4 \%$ & $4(+2)$ & $88,8 \%$ \\
\hline 6 & $89,3 \%$ & $4(+1)$ & $91,7 \%$ & $1(-2)$ & $93,8 \%$ & $8(+4)$ & $96,4 \%$ & $8(+4)$ & $93,6 \%$ & $1(-2)$ & $87,9 \%$ \\
\hline 4 & $89,0 \%$ & $6(-1)$ & $91,2 \%$ & $8(+3)$ & $93,3 \%$ & $2(+4)$ & $96,0 \%$ & $1(-3)$ & $93,5 \%$ & $6(-1)$ & $86,7 \%$ \\
\hline 7 & $88,7 \%$ & 7 & $90,9 \%$ & $6(-2)$ & $93,2 \%$ & $10(+1)$ & $95,7 \%$ & $6(-2)$ & $93,4 \%$ & $8(+2)$ & $86,6 \%$ \\
\hline 10 & $87,6 \%$ & 10 & $90,3 \%$ & $7(-1)$ & $93,1 \%$ & $7(-1)$ & $95,3 \%$ & $7(-1)$ & $93,4 \%$ & $7(-1)$ & $86,5 \%$ \\
\hline 8 & $87,1 \%$ & 8 & $90,2 \%$ & $2(+1)$ & $93,0 \%$ & $6(-4)$ & $95,1 \%$ & $10(-1)$ & $93,1 \%$ & $10(-1)$ & $86,1 \%$ \\
\hline 2 & $87,0 \%$ & 2 & $90,0 \%$ & $10(-2)$ & $93,0 \%$ & $1(-7)$ & $95,0 \%$ & 2 & $92,8 \%$ & 2 & $86,1 \%$ \\
\hline 5 & $84,6 \%$ & 5 & $84,7 \%$ & 5 & $84,8 \%$ & 5 & $84,9 \%$ & 5 & $84,8 \%$ & 5 & $72,0 \%$ \\
\hline 9 & $84,4 \%$ & 9 & $84,5 \%$ & 9 & $84,7 \%$ & 9 & $84,8 \%$ & 9 & $84,7 \%$ & 9 & $71,7 \%$ \\
\hline
\end{tabular}

Fonte: Elaboraçấo própria. Legenda: 1 - Casal sem filhos e sem outros parentes; 2 Casal sem filhos e com outros parentes; Casal com filhos e sem outros parentes; 4 - Casal com filhos e com outros parentes; 5 - Homem solteiro sem filhos e sem outros parentes; 6 - Homem solteiro sem filhos e com outros parentes; 7 - Homem solteiro com filhos e sem outros parentes; 8 - Homem solteiro com filhos e com outros parentes; 9 - Mulher solteira sem filhos e sem outros parentes; 10 - Mulher solteira sem filhos e com outros parentes; 11 - Mulher solteira com filhos e sem outros parentes; 12 - Mulher solteira com filhos e com outros parentes.

da tradicional para a décima posição na medida de alfabetização efetiva com externalidade avaliada em 0,75 . Esse resultado indica a pouca presença de ANI em domicílios com tal perfil em relação aos demais. Já o arranjo domiciliar homem solteiro com filhos e com outros parentes (arranjo 8) apresenta, em praticamente todas as outras medidas, resultado superior a que obtém na medida tradicional $(87,6 \%)$. Destaca-se o fato de que, na medida de Subramanian (2004), esse arranjo domiciliar sobe duas posiçóes, o que indica melhor situação em termos de ausência de analfabetismo isolado.

Dado que tanto os resultados descritivos quanto a aplicação das medidas de alfabetização identificam que a maior parcela dos AIs está situada na região Nordeste, investigam-se eventuais desigualdades da alfabetização entre os municípios dos Estados dessa região. Este estudo com abrangência geográfica mais detalhada é importante para a focalização de políticas públicas. Acredita-se que possa haver dentro dos Estados do Nordeste má dis- 
tribuição da alfabetização, o que seria revelado com a aplicação das medidas para os municípios dessa região.

Como a PNAD não permite a identificação dos municípios brasileiros, utiliza-se para o cumprimento da finalidade exposta acima o Censo Demográfico de 2000. Cabe destacar que o número de observaçóes obtidas apenas com os Estados da região Nordeste é de 1.787 municípios.

A Figura 4.1, ao lado, apresenta cinco gráficos. Em cada um deles, no eixo horizontal, está a posição do município no ranking da medida tradicional, e no eixo vertical está a posição do município no ranking de alguma das medidas expostas neste estudo. Percebe-se, pela análise dos três gráficos da parte de cima da figura, que, à medida que se aumenta a magnitude das externalidades da $A E$, maior é a alteração dos rankings, como já havia sido constatado quando se fez a análise por Estados. Isso é captado pelo aumento da dispersão dos pontos nos gráficos posicionados da esquerda para a direita. Para uma magnitude de 0,25 (primeiro gráfico superior da Figura 1), os pontos estão situados bem próximos a uma linha imaginária de 45 graus (o coeficiente de determinação da equação de tendência, 0,9958 , junto com o baixo valor do intercepto dessa equação, 1,8597, revela isso), o que indica baixa variação entre a utili- zação de $T$ e $A E(0,25)$. Agora, supondo uma magnitude de 0,75 para as externalidades, há maior dispersão dos pontos no gráfico (coeficiente de determinação da equação de tendência é menor, 0,9171), o que indica maior alteração nos rankings (terceiro gráfico superior na Figura 1). Para as medidas $A S D$ e $A A E$, constatam-se resultados similares ao da associação entre $T$ e $A E$ (0.5) (primeiro e segundo gráficos da parte inferior e segundo gráfico da parte superior da Figura 4.1).

Por fim, para entender os fatores associados às variações dos rankings apresentados nos gráficos da figura acima, procedeu-se a estimação de regressôes de uma variável padrão obtida com base na diferença das posiçóes no ranking da medida tradicional em relação às medidas alternativas sobre características da população dos municípios. A busca dos fatores associados às variações das medidas auxilia na identificação e na confirmaçáo dos resultados obtidos da descrição do perfil de alfabetização da população. As variáveis utilizadas são a proporção de não brancos, proporção de homens, proporção de moradores na zona rural, proporção de pessoas em cada faixa etária utilizada neste estudo e a proporção de pessoas residentes em cada tipo de arranjo domiciliar nos municípios do Nordeste. Os resultados estão presentes na Tabela 4.9. 
Figura 4.1_Gráficos de dispersão dos rankings da medida tradicional com as medidas alternativas de alfabetização para os municípios da região Nordeste
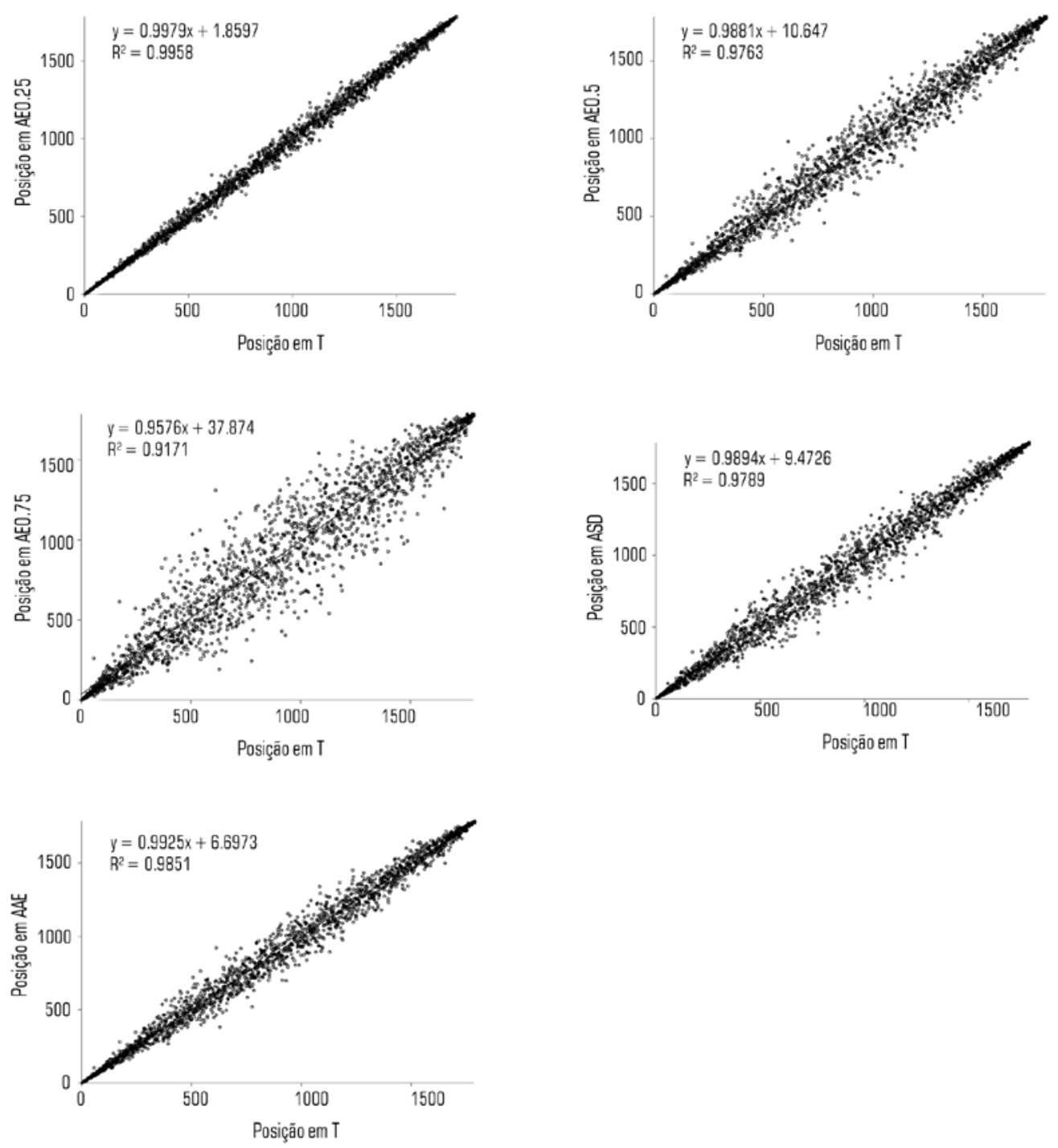

Fonte: Elaboração própria. 
Tabela 4.9_Regressões para a identificação das características demográficas associadas à variação nos rankings de alfabetização no Nordeste

\begin{tabular}{|c|c|c|c|c|c|}
\hline Variáveis & $\begin{array}{l}\text { Var dep: } \\
\text { R-AEO25 } \\
\text { coef/dp }\end{array}$ & $\begin{array}{l}\text { Var dep: } \\
\text { R-AE025 } \\
\text { coef/dp }\end{array}$ & $\begin{array}{l}\text { Var dep: } \\
\text { R-AE025 } \\
\text { coef/dp }\end{array}$ & $\begin{array}{l}\text { Var dep: } \\
\text { R-AE025 } \\
\text { coef/dp }\end{array}$ & $\begin{array}{l}\text { Var dep: } \\
\text { R-AE025 } \\
\text { coef/dp }\end{array}$ \\
\hline \multirow[t]{2}{*}{ Prop. Não Brancos } & 0.041 & 0.009 & -0.036 & -0.056 & 0.012 \\
\hline & $(0.213)$ & $(0.214)$ & $(0.218)$ & $(0.202)$ & $(0.213)$ \\
\hline \multirow[t]{2}{*}{ Prop. Homen } & 2.876 & 2.453 & 2.202 & -1.207 & 2.731 \\
\hline & $(1.982)$ & $(1.994)$ & $(2.002)$ & $(1.873)$ & $(2.001)$ \\
\hline \multirow[t]{2}{*}{ Prop. Rural } & -0.227 & -0.178 & -0.127 & 0.202 & -0.182 \\
\hline & $(0.145)$ & $(0.144)$ & $(0.142)$ & $(0.142)$ & $(0.145)$ \\
\hline \multirow[t]{2}{*}{ Prop. Jovens } & -0.864 & -1.244 & -1.781 & 1.236 & -1.123 \\
\hline & $(1.609)$ & $(1.599)$ & $(1.592)$ & $(1.575)$ & $(1.597)$ \\
\hline \multirow[t]{2}{*}{ Prop. Adultos } & $1.874^{*}$ & 1.433 & 0.557 & $2.210^{* *}$ & 1.694 \\
\hline & $(1.105)$ & $(1.113)$ & $(1.123)$ & $(1.054)$ & $(1.110)$ \\
\hline \multirow[t]{2}{*}{ Prop. Idosos } & -0.757 & -0.926 & -1.430 & $3.229^{* *}$ & -0.819 \\
\hline & $(1.315)$ & $(1.323)$ & $(1.330)$ & $(1.310)$ & $(1.325)$ \\
\hline \multirow[t]{2}{*}{ Prop. Arranjo1 } & -3.651 & -1.800 & 3.584 & -2.210 & -1.271 \\
\hline & $(3.316)$ & $(3.296)$ & $(3.603)$ & $(3.589)$ & $(3.311)$ \\
\hline \multirow[t]{2}{*}{ Prop. Arranjo2 } & 1.601 & 2.753 & $7.447^{*}$ & 3.556 & 3.346 \\
\hline & $(3.987)$ & $(3.983)$ & $(4.230)$ & $(4.114)$ & $(4.009)$ \\
\hline \multirow[t]{2}{*}{ Prop. Arranjo3 } & 3.890 & 5.146 & $9.637^{* * *}$ & $6.448^{*}$ & $5.814^{*}$ \\
\hline & $(3.334)$ & $(3.310)$ & $(3.610)$ & $(3.564)$ & $(3.334)$ \\
\hline \multirow[t]{2}{*}{ Prop. Arranjo4 } & $6.202^{*}$ & $7.514^{* *}$ & $12.123^{* * *}$ & $8.181^{* *}$ & $8.164^{* *}$ \\
\hline & $(3.256)$ & $(3.236)$ & $(3.541)$ & $(3.509)$ & $(3.255)$ \\
\hline \multirow[t]{2}{*}{ Prop. Arranjo5 } & $-37.996^{* * *}$ & $-37.766^{* * *}$ & $-34.495^{* * *}$ & $-24.432^{* * *}$ & $-37.536^{* * *}$ \\
\hline & $(5.384)$ & $(5.369)$ & $(5.551)$ & $(5.280)$ & $(5.408)$ \\
\hline \multirow[t]{2}{*}{ Prop. Arranjo6 } & -6.097 & -5.099 & -1.249 & -1.161 & -4.147 \\
\hline & $(5.649)$ & $(5.638)$ & $(5.830)$ & $(5.722)$ & $(5.659)$ \\
\hline
\end{tabular}




\begin{tabular}{|c|c|c|c|c|c|}
\hline Variáveis & $\begin{array}{l}\text { Var dep: } \\
\text { R-AE025 } \\
\text { coef/dp }\end{array}$ & $\begin{array}{l}\text { Var dep: } \\
\text { R-AE025 } \\
\text { coef/dp }\end{array}$ & $\begin{array}{l}\text { Var dep: } \\
\text { R-AE025 } \\
\text { coef/dp }\end{array}$ & $\begin{array}{l}\text { Var dep: } \\
\text { R-AE025 } \\
\text { coef/dp }\end{array}$ & $\begin{array}{l}\text { Var dep: } \\
\text { R-AEO25 } \\
\text { coef/dp }\end{array}$ \\
\hline \multirow[t]{2}{*}{ Prop. Arranjo7 } & -2.285 & 1.273 & 7.309 & 4.065 & 1.219 \\
\hline & (5.019) & $(4.950)$ & $(5.131)$ & $(4.902)$ & $(4.988)$ \\
\hline \multirow[t]{2}{*}{ Prop. Arranjo8 } & $13.844^{* * *}$ & $14.945^{* * *}$ & $18.596^{* * *}$ & 7.854 & $15.843^{* * *}$ \\
\hline & $(5.176)$ & (5.209) & $(5.430)$ & $(5.162)$ & $(5.186)$ \\
\hline \multirow[t]{2}{*}{ Prop. Arranjo9 } & $-23.341^{* * *}$ & $-22.364^{* * *}$ & $-17.117^{* *}$ & $-27.328^{* * *}$ & $-21.712^{* * *}$ \\
\hline & $(6.985)$ & $(6.924)$ & $(6.979)$ & $(6.462)$ & $(6.951)$ \\
\hline \multirow[t]{2}{*}{ Prop. Arranjo10 } & -1.628 & -1.081 & 3.186 & -2.977 & -0.199 \\
\hline & $(5.301)$ & $(5.308)$ & $(5.515)$ & $(5.472)$ & $(5.330)$ \\
\hline \multirow[t]{2}{*}{ Prop. Arranjo11 } & 3.627 & 4.661 & $9.005^{* *}$ & 2.527 & 5.466 \\
\hline & $(3.710)$ & $(3.703)$ & $(3.987)$ & $(3.935)$ & $(3.729)$ \\
\hline \multirow[t]{2}{*}{ Prop. Arranjo12 } & 2.222 & 3.455 & $8.069^{* *}$ & 4.748 & 4.199 \\
\hline & $(3.647)$ & $(3.590)$ & (3.839) & (3.794) & $(3.621)$ \\
\hline Observaçóes & $1,787$. & $1,787$. & $1,787$. & 1,787 . & $1,787$. \\
\hline
\end{tabular}

Fonte: Elaboração própria. Nota: ${ }^{* * *} \mathrm{p}<0.01,{ }^{* *} \mathrm{p}<0.05,{ }^{*} \mathrm{p}<0.1$ Legenda: 1 - Casal sem filhos e sem outros parentes; 2 - Casal sem filhos e com outros parentes; 3 - Casal com filhos e sem outros parentes; 4 - Casal com filhos e com outros parentes; 5 - Homem solteiro sem filhos e sem outros parentes; 6 - Homem solteiro sem filhos e com outros parentes; 7 - Homem solteiro com filhos e sem outros parentes; 8 - Homem solteiro com filhos e com outros parentes; 9 - Mulher solteira sem filhos e sem outros parentes; 10 - Mulher solteira sem filhos e com outros parentes; 11 - Mulher solteira com filhos e sem outros parentes; 12 - Mulher solteira com filhos e com outros parentes.

Os resultados mostrados na Tabela 4.9 apontam robustamente que a proporção de pessoas presentes nos arranjos domiciliares homens ou mulheres chefes de família solteiros sem filhos e sem outros parentes (arranjos domiciliares 5 e 9) estão entre os principais fatores associados a alteraçóes nos rankings de alfabetização. Os coeficientes estimados (todos significantes a $1,0 \%$ ) possuem sinal negativo, o que revela que a posição dos municípios com maior proporçáo de pessoas residindo nesses arranjos domiciliares se situa em pior colocaçáo nos rankings das medidas alternativas à tradicional, que levam em conta as possíveis externalidades da alfabetização e/ou a proporção de AI. Esse resultado está de acordo com a já obser- 
vada grande proporção de AI no total da população das pessoas que residem em arranjos domiciliares com chefe de domicilio solteiro sem filhos e sem outros parentes. Por fim, outro resultado robusto e que confirma constataçóes anteriores é que a proporção de pessoas no arranjo domiciliar homem chefe de domicilio solteiro com filhos e com outros parentes (arranjo 8) também exerce influência na alteração dos rankings.

\section{Considerações finais}

Este trabalho contribui para o debate de alfabetização no Brasil por apresentar os conceitos de Analfabetismo Isolado e Externalidades da Alfabetização, que são úteis para a implantação de políticas públicas de alfabetização. A investigação da distribuição e do perfil de alfabetização no país sob esses conceitos revelou principalmente que a maior parte dos AIs está localizada na regiáo Nordeste, o que sugere o direcionamento dos esforços de políticas públicas para tal região. Outra constatação importante é que a maior parte dos AIs diz respeito a pessoas idosas da população brasileira e que, em arranjos domiciliares nos quais o chefe do domicilio é solteiro e não tem filhos e outros parentes, o percentual de AI é bastante elevado.

Também foi constatado que, tanto para os Estados do Brasil, em 2009, quan- to para os municípios do Nordeste, em 2000, há variação (crescente na medida em que aumenta a magnitude das externalidades) entre os resultados da medida tradicional com os resultados das medidas alternativas. No caso dos municípios dos Estados da Região Nordeste, o tipo de arranjo domiciliar chefe de domicilio homem ou mulher solteiro(a) sem filhos e sem outros parentes é o principal responsável pela variação dos rankings. Esses resultados condicionam políticas públicas de alfabetização à região Nordeste, à populaçáo idosa e aos arranjos domiciliares com o perfil descrito acima.

No entanto, é preciso dizer que os resultados obtidos das aplicaçóes das medidas estão condicionados a dois fatos: i) nos exercícios realizados, foram estipulados ad hoc os valores para as externalidades, ou especificada uma forma funcional para as externalidades, e ii) assumiu-se implicitamente a hipótese de homogeneidade das externalidades entre as observações. Fica em decorrência disso a necessidade de próximos estudos que estimem a magnitude das externalidades da alfabetização nos diferentes Estados e grupos demográficos, como fazem os estudiosos da linha empírica de externalidades da alfabetização. 


\section{Referências bibliográficas}

\author{
ALMEYDA-DURAN, R. Proximate \\ literacy, inter and intrahousehold \\ externalities and child health \\ outcomes: Evidence from India. \\ Mimeo. Columbia University: \\ New York, NY, 2005. \\ BARROS. R. P.; CARVALHO. M \\ \& FRANCO. S. Analfabetismo \\ no Brasil. 2004. Disponível \\ em: <http://www.iets.org.br/ \\ biblioteca/Analfabetismo_ \\ no_Brasil.pdf >. Acesso em: \\ 03/02/2010.
}

BASU, K. \& FOSTER, J. On measuring literacy. Economic Journal, vol. 108, p. 173-349, 1998.

BASU, K.; FOSTER, J.; FOSTER \& SUBRAMANIAN. S. Isolated and proximate illiteracy and why these concepts matter in measuring literacy and designing education programmes. Economic and Political Weekly, vol. 35, p. 35-38, 2000.

BASU. K. \& LEE. T. A new and easy-to-use measure of literacy, its axiomatic properties and an application. Working Papers 0804, Cornell University, Center for Analytic Economics. 2008.
BASU. K.; NARAYAN., A.; NARAYAN \& RAVALLION. M. Is literacy shard within households? Theory and Evidence from Bangladesh. Journal of Labor Economics, vol. 8, p. 649-655, 2002.

BELTRĀO. K \& NOVELLINO. M. Alfabetização por raça e sexo no Brasil: Evolução no período 1940 e 2000. Escola Nacional de Ciências Estatísticas, IBGE, 2002.

DE BALDINI ROCHA, M. S.; PONCZEK, V. P. The effects of adult literacy on earnings and employment. Economics of Education Review, vol. 30, p. 755-764, 2011.

DUTTA, I. Generalized measures of literacy. Mathematical Social Sciences, 48, p. 68-90, 2004.

GIBSON. J. Literacy and intrahousehold externalities. World Development, vol. 29, p. 155-166, 2001.

GREEN, S. E.; RICH, T. A \& NESMAN E. G. Beyond individual literacy: The role of shared literacy for innovation in Guatemala. Human Organization, vol. 44, p. 313-21, 1985.

LEE. T. Benchmarking the effective literacy rate. Mathematical Social Sciences, vol. 56, p. 233-239, 2008.
MADDOX. B. Worlds apart? Ethnographic reflections on "effective literacy" and intrahousehold externalities. World Development, vol. 35, p. 532-541, 2007.

MEDEIROS, M.; OSORIO, R. G. Mudanças na composição dos arranjos domiciliares no Brasil 1978 a 1998. Revista Brasileira de Estudos de População (Impresso), v. 17, n. 1/2, p. 67-85, 2000.

MISHRA S. Isolated and proximate illiteracy. Economic and Political Weekly, vol. 36,

n. 22, p. 2003-2008, 2001.

MUKHERJEE. D. \& GUPTA. M. R. Measures of effective literacy: A theoretical and empirical note. Hitotsubashi Journal of Economics, vol. 47, p. 17-35, 2006.

SOUZA, M. M. O Analfabetismo no Brasil sob o enfoque demográfico. IPEA. Textos para Discussão. Brasília, 1999.

SUBRAMANIAN, S. Measuring literacy: Some extensions of the Basu-Foster framework. Journal of Development Economics, vol. 73, p. 453-463, 2004.
VALENTI. P. M. Should we be concerned about the distribution of the literacy across households? An Axiomatic Investigation. $C A E$ Working Paper \#02-15, 2002.

Disponível em: <www.arts. cornell.edu/econ/cae/Valenti_ Literacy.pdf $>$. Acesso em: 23/06/2008. 
